\title{
LOS PASOS ANDINOS DE LA RIOJA (ARGENTINA): LA DOMINACIÓN INCA Y EL DERROTERO DE DIEGO DE ALMAGRO
}

\author{
THE ANDEAN MOUNTAIN PASSES OF LA RIOJA (ARGENTINA): \\ INKA DOMINATION AND THE DEFEAT OF DIEGO DE ALMAGRO
}

\author{
J. RoBerto BÁrCENA
}

\begin{abstract}
Nuestros pioneros avances permitieron reconocimientos de sitios arqueológicos e itinerarios de altura hacia la vertiente occidental de los Andes. Estos incluyeron excavaciones y estudios de materiales de instalaciones que presentan ocupaciones temporales (c. 800 al $1480 \mathrm{AD}$ ), registrando la impronta del conspicuo Período Inca (c. 1470 al 1536 AD) y alcanzando su utilización hasta la primera mitad del siglo XIX). Nuestra hipótesis, si bien considera posibles las posiciones de colegas que proponen para el derrotero de Almagro un abanico de pasos que van desde Peña Negra a Pircas Negras, con sus desechos y con Comecaballos como paso central, señala a la quebrada del arroyo Peña Negra y al paso de La Ollita con suficiente probabilidad como uno de los pasos transitados, tal vez el más importante.

Palabras clave: pasos andinos, derroteros, Inca, Almagro, La Rioja argentina.
\end{abstract}

Our pioneering research led to the discovery of archaeological sites and high-altitude routes on the western side of the Andes. This included excavations and studies of materials form sites exhibiting temporary occupations (c. 800 to $1480 \mathrm{AD}$ ) that pointed clearly to the Inca period (c.1470 to $1536 \mathrm{AD}$ ) and later, up to the first half of the nineteenth century. While acknowledging other colleagues' positions that consider a wide range of other mountain passes, from Peña Negra to Pircas Negras, among which Comecaballos was the most important, out hypothesis argues that the Negra ravine and, particularly, the paso de la Ollita were not only some of the most traveled mountain passes, but also very likely the main ones.

Keywords: Andean mountain passes, Roads, Inca, Almagro, La Rioja argentina.

\section{INTRODUCCIÓN}

Subsidios del CONICET, de la ANPCyT y autorizaciones de las instituciones gubernamentales patrimoniales correspondientes facilitan que trabajemos con nuestro equipo de investigaciones en el oeste de La Rioja y noroeste de San Juan, principalmente tras las evidencias de la época de dominación Inca Regional. Nuestro objetivo es reconocer la infraestructura de ese origen y de las poblaciones de los Desarrollos Regionales relacionadas con la misma, entre otros, en los pasos cordilleranos que vinculan ambas vertientes andinas.

En los casos de las quebradas y pasos riojanos de Pircas Negras, Comecaballos, Peña Negra, La Ollita y los respectivos desechos ${ }^{1}$ del área de influencia de la Reserva Provincial Laguna Brava, descubrimos sitios arqueológicos que abarcan un amplio lapso de la prehistoria del área. Nos dedicamos en particular a los de época Inca, a su vinculación con poblaciones locales, con la posterior presencia hispánica y con la postrera y recurrente acción de los arrieros en la época independiente, la que alcanza las primeras décadas del siglo xx.

En el caso particular del sector del paso de La Ollita, que remontamos hasta $4700-4850 \mathrm{msnm}$, sumamos a nuestro hallazgo anterior de un tambo incaico en la zona,

\footnotetext{
A J. Roberto Bárcena, INCIHUSA-CONICET, IAE/FFyl-UnCuyo, UnLaR; INCIHUSA-CONICET, CC 131, 5500, Mendoza, Argentina, email: rbarcena@mendoza-conicet.gob.ar
} 
el descubrimiento de otros dos grupos de construcciones de ese período al pie del paso, siempre del lado argentino. Uno de ellos, según nuestra interpretación, es un posible ushnu o conjunto de plataformas ceremoniales que tendrían escalinata de acceso. El otro grupo, donde reconocimos además impronta incaica en parte de sus construcciones, tiene por base estructuras pircadas como recintos circulares y semicirculares, tratándose en este último caso de los típicos parapetos utilizados para la caza de camélidos como la vicuña y el guanaco, que en otras partes del área cordillerana hemos datado aproximadamente entre el 900 y $4000 \mathrm{AD}$.

Por su parte, el área de Comecaballos nos permitió reconocer también los parapetos característicos en relación con el curso del arroyo homónimo, así como entierros del siglo vir al Ix en el paso, visibles en superficie sus continentes por su apariencia de montículos. Además, determinamos infraestructura inca sobre sitios arqueológicos preexistentes del trayecto hacia el paso. Observamos también evidencia del traslado moderno de ganado en pie, sin que nuestro registro haya podido incluir vestigios del paso de las huestes de Diego de Almagro como se ha propuesto, ni de las probadas históricamente, del paso de una de las columnas del Ejército Libertador de San Martín hacia Copiapó, lugar que, pre e históricamente ha sido y es el núcleo principal de población chilena más cercano al área que nos ocupa.

Las áreas tratadas aquí corresponden a ambientes de altura por sobre los 3000 y $4000 \mathrm{msnm}$, alcanzando cotas de 4500 msnm o más, correspondientes al ámbito andino y puneño, en zonas de la Reserva Provincial Laguna Brava en La Rioja o bien de la Reserva de la Biósfera, como es el Parque Nacional San Guillermo en el norte extremo de San Juan, colindante por el sur con la anterior. Ambas reservas son notables por sus poblaciones de vicuñas y de guanacos, acompañadas por una variada fauna de altura, vegetación acorde y cursos endorreicos, o no, con lagunas salinas y rodeadas de cimas que sobrepasan los 5000 msnm (fig. 1).

En rigor, los dos ámbitos destacan por sus mesetas, llanos de altura ricos en gramíneas aprovechadas por la fauna de vicuñas ${ }^{2}$ y guanacos, con sus subidas hacia las mayores alturas montañosas de los pasos cordilleranos por quebradas. En ellas, a los cursos de agua se suman vegas que son refugio de los camélidos, así como también las bajadas desde los llanos hacia el colector Río Blanco, en muchos casos con vegas, permitiendo la movilidad de esa fauna.
La apropiación de estos espacios debió ser de interés desde tiempos prehistóricos y continúa siéndolo hasta la actualidad, como se aprecia en la materialidad cultural del sector. Con la dominación inca se alcanzó la estabilización de un patrón de instalación y probablemente de producción económica, en buena medida con base en la infraestructura preexistente, reutilizándola y remodelándola según sus propias plantas arquitectónicas o implantándola desde el origen según sus modelos.

Esta última presencia es la que abordamos principalmente con nuestras investigaciones, planteando una aproximación desde el paisaje que admite parangón con otros cuya preferencia y manejo es habitual para la organización estatal a lo largo de los Andes. Esto porque, tras el producido por pelos y lanas, carnes y otros, de camélidos (Vicugna vicugna, Lama guanicoe) y por plumas de aves migratorias como los flamencos o parinas (chica y grande; Phoenicoparrus jamesi y Phoenicoparrus andinus; Phoenicoparrus chilensis), adecua el espacio con su infraestructura, tanto para las actividades extractivas como para las de circulación, para las votivas de los altos cerros y las de seguridad territorial en un área bisagra, hinterland, entre dos conspicuas del Período de los Desarrollos Regionales o, si se quiere, de las organizaciones socio-político-económicas regionales a nivel de las jefaturas, como son las del NOA y las del norte chico y sector austral del norte grande chileno.

En los hallazgos de manufacturas en metales que reputamos no indígenas y producidas en otros lugares, no encontramos -ni sabemos que lo hayan hecho colegas en el área- indicios que apunten a la minería prehispánica, aunque cabe señalar que pudo ser este otro factor importante en la ocupación, dada la relevancia de los veneros de la zona, hoy explorados en los entornos de San Guillermo y Laguna Brava con fines comerciales, tras el oro, el cobre y la plata.

Hace una veintena de años, arqueólogos que nos precedieron con una prospección general en San Guillermo, sin avanzar luego con proyectos en el área, esbozaron hipótesis sobre tambos que fungirían para el manejo de vicuñas (Gambier \& Michieli 1992). En otros casos, para los actuales pasos internacionales en el suroeste de La Rioja, algunos colegas aludieron a Comecaballos como el paso posible para Diego de Almagro y sus huestes en 1536 AD. Uno de ellos lo propuso como propio del pasaje hispánico primero allende la cordillera en esta parte de los Andes, sin que sepamos si el investigador accedió personalmente a estas áreas, fundando 

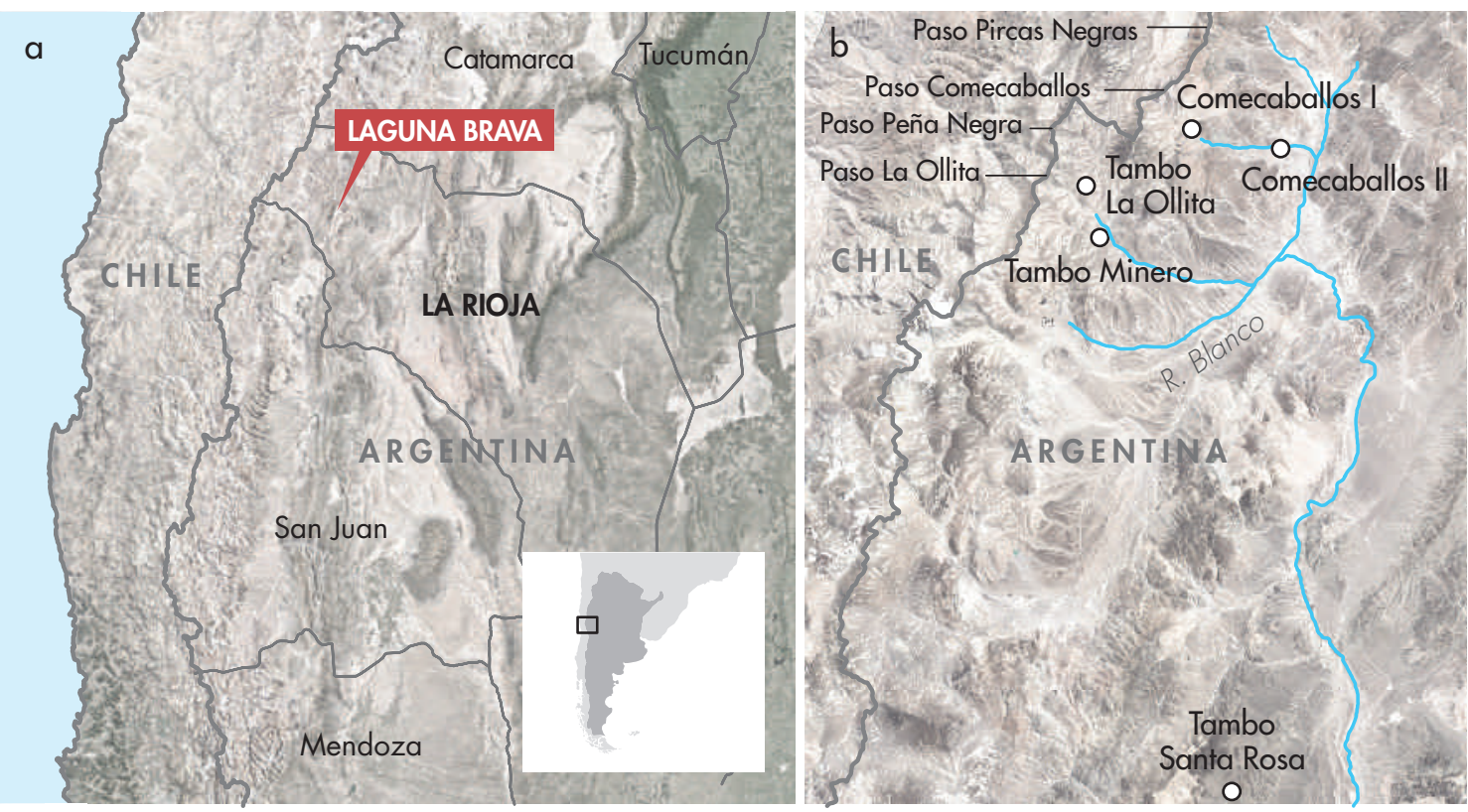

Figura 1: a) mapa de la región central y norte de Argentina, con la ubicación de Laguna Brava y sector de los pasos tratados aquí; sitos en el oeste de la Provincia de La Rioja; b) posición de quebradas/ríos/arroyos, pasos y sitios arqueológicos descritos en el texto. Figure 1: a) map of the central and northern Argentina, depicting the location of Laguna Brava and the area of the mountain passes discussed here; sites in the west of La Rioja Province; $\boldsymbol{b}$ ) location of ravines/creeks/rivers, mountain passes and archaeological sites described in the text.
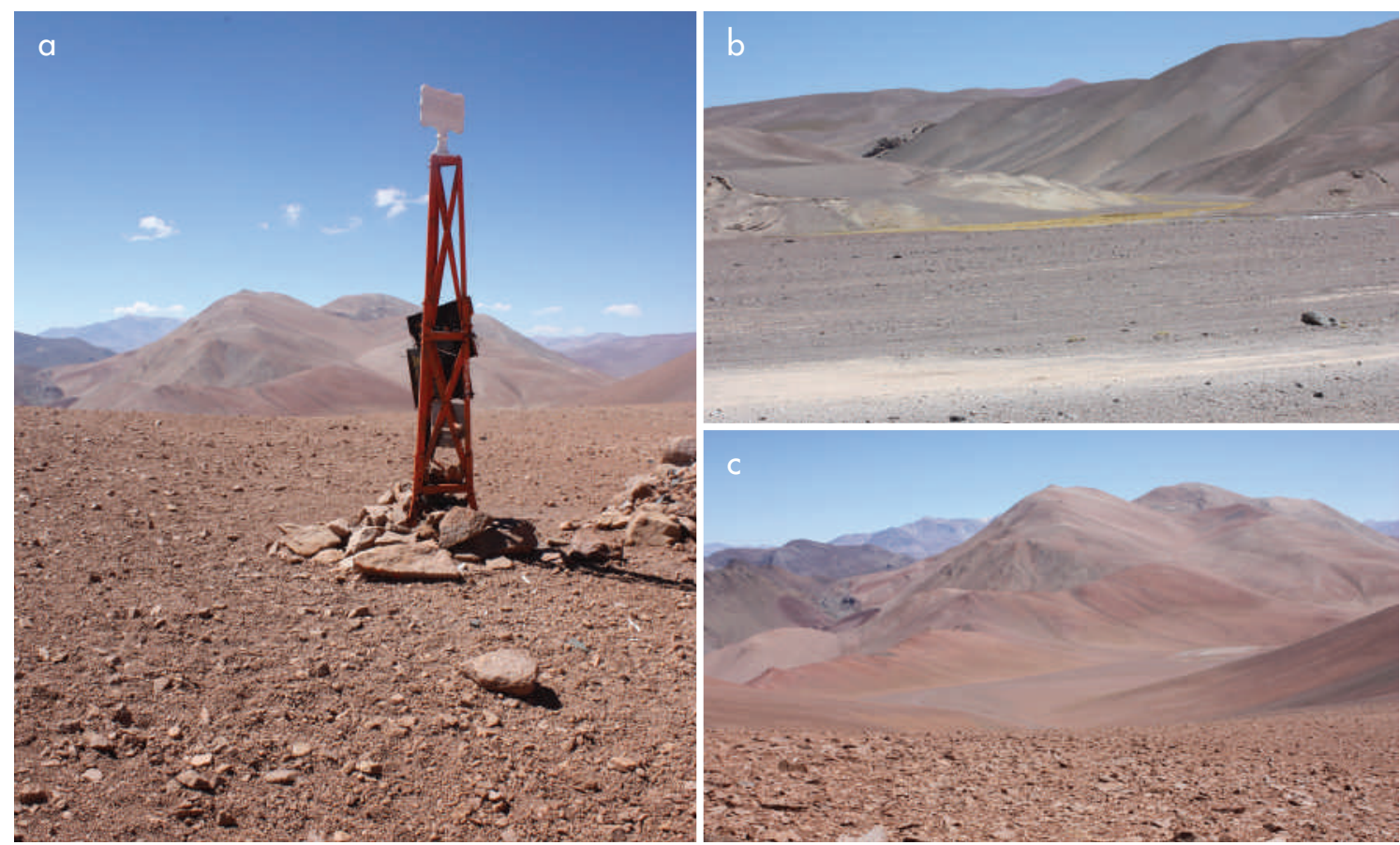

Figura 2: a) vista general del paso de Comecaballos (La Rioja, Argentina); b) vista general de la desembocadura del arroyo Comecaballos en el Río Salado; c) vista del paso de Comecaballos en su descenso al lado chileno. Figure 2: a) general view of the Comecaballos mountain pass (La Rioja, Argentina); $\boldsymbol{b}$ ) general view of the mouth of the Comecaballos creek into the Salado River; $\boldsymbol{c}$ ) view from the Comecaballos mountain pass down to the Chilean side. 


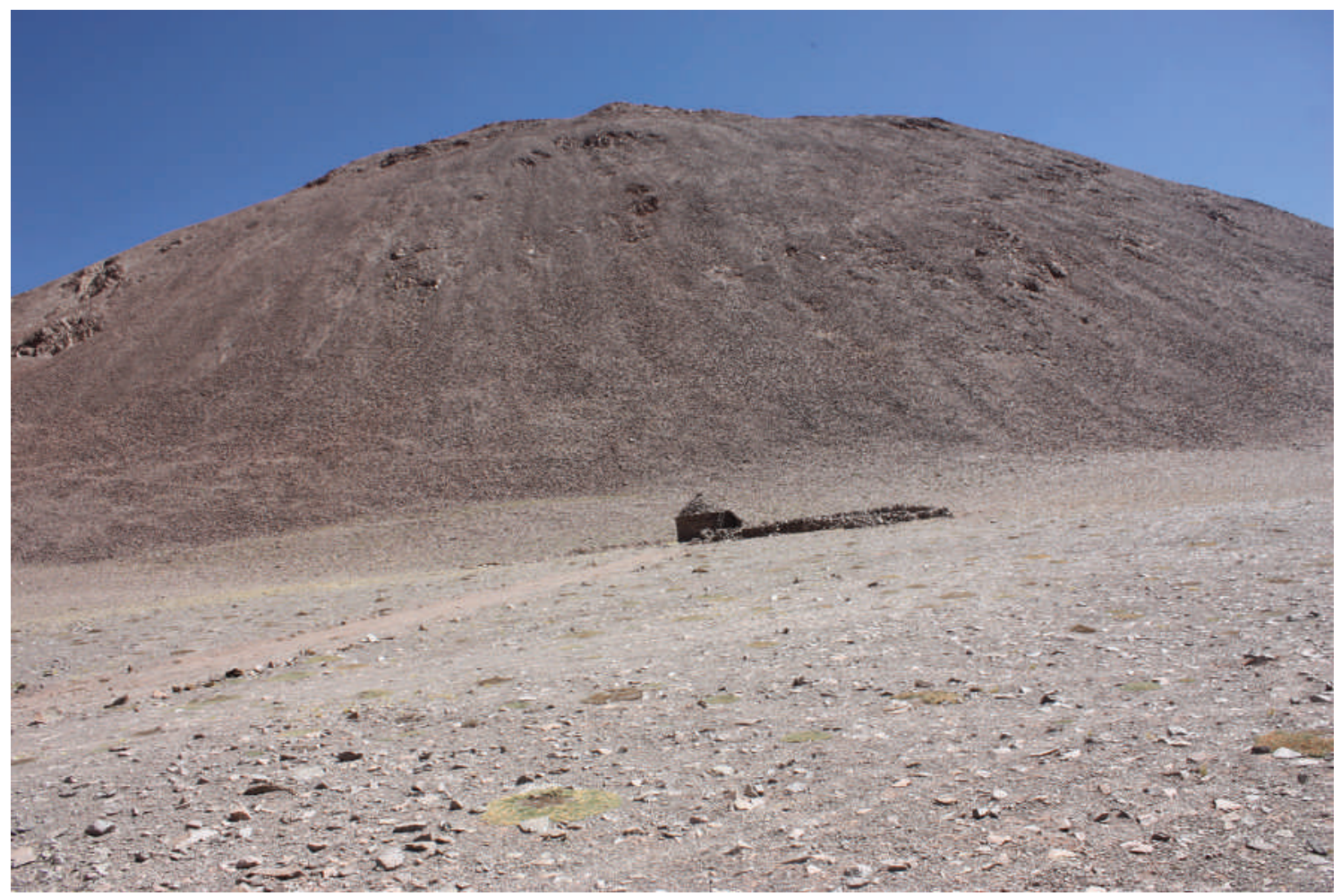

Figura 3. Refugio de Comecaballos, construido hacia el último tercio del siglo xIx para pernocte de personas, y de animales en el corral anexo, integrantes de los arreos de ganado mayor a Chile. Figure 3. Comecaballos refuge, built in the final third of the 19th century for overnight stays by people and animals (in the adjoining corral) as part of cattle driving that brought herds to Chile.

principalmente su hipótesis en labores realizadas en el lado chileno del sector y en la revisión bibliográfica (Raffino 1995; Bárcena 2007, 2015). Creemos que esa labor de los colegas solo tendría resultados contrastables y verificables estableciendo proyectos de largo alcance, que implicaran sumar a prospecciones intensivas en tan dilatadas y difíciles áreas -desde la perspectiva logística- excavaciones y estudios sistemáticos, como venimos haciendo con continuidad anual desde hace más de una década. En este sentido, además de las prospecciones contamos con resultados de nuestras excavaciones en los tambos de La Alcaparrosa y Santa Rosa, estando en curso las del Tambo Pircas Blancas, todos en el Parque Nacional San Guillermo.

En cuanto a las labores en la Reserva de Laguna Brava y zona de influencia reconocimos numerosas instalaciones prehistóricas excavando los sitios relacionados con la presencia inca en la quebrada y paso de Comecaballos, en el sector de un arroyo subsidiario del arroyo Peña Negra, sitio que denominamos Tambo
Minero, y en el sector de otro subsidiario de este último arroyo, sitio que llamamos Tambo de La Ollita y que se halla al pie del paso homónimo.

Por lo tanto, con la presente contribución nos proponemos alcanzar el conocimiento arqueológico de los pasos cordilleranos del centro oeste de La Rioja, la infraestructura incaica presente y su mejor aptitud para la comunicación trasandina, en su relación con la documentación histórica. Al mismo tiempo, buscamos introducirnos en la discusión sobre el o los pasos cordilleranos del actual límite argentino-chileno, utilizado(s) por Diego de Almagro y sus huestes camino de Copiapó.

\section{Resultados}

\section{La quebrada y paso de Comecaballos}

La desembocadura de esta quebrada y arroyo homónimo corresponde al Río Salado (ca. $3800 \mathrm{msnm}$ ), afluente del Río Blanco. Remontándola se accede al hito del límite 
internacional Argentina/Chile (ca. $4500 \mathrm{msnm}$; a unos $20 \mathrm{~km}$ de distancia) (fig. 2).

Comecaballos fue un paso estratégico por el relativo fácil acceso a Copiapó, al Copayapu que luego se generalizaría como Chili en las crónicas de la conquista. La situación es confirmada por hechos históricos, como por ejemplo los de la época de las luchas por la independencia nacional de Argentina y de Chile, protagonizados por la columna sanmartiniana que, desde varias localidades riojanas, procedieron a Guandacol y de allí, por el paso, a Chile, permitiendo la toma de Copiapó, Huasco y Coquimbo.

Utilizado para el traslado de vacunos hacia Chile, es uno de los pasos conocidos por los arrieros andinos de todos los tiempos. Esto implicó que, en la última parte del siglo XIX, el gobierno argentino levantara allí uno de tantos refugios para los arrieros, con factura de piedras y argamasa, el que persiste prácticamente incólume (fig. 3).

El paso registra una larga historia de usos, lo que sin duda fue considerado por los estrategas de la victoriosa campaña libertadora que se rememora año a año. ${ }^{1}$

La utilidad del paso y los recursos de fauna del sector fueron aliciente para la instalación en la época de dominación inca, tal como lo demuestran los establecimientos de la quebrada. Según los autores, ello tendría relación con el primer ingreso sistemático hispano al NOA y el paso a Chile, con Diego de Almagro a la cabeza (1535/1536 AD).

Autores dedicados a colegir el sector de paso de los Andes empleado por el adelantado y sus huestes ofrecieron diversos argumentos sobre esta posibilidad, destacando entre ellos R. A. Raffino (1995, 2004; Raffino et al. 2001), quien contrastó datos arqueológicos con los documentales históricos del paso de Almagro, aunque sin realizar investigaciones de terreno del lado argentino del paso, quebrada y arroyo de Comecaballos. ${ }^{2}$

Nuestros estudios arqueológicos en la quebrada del arroyo de Comecaballos y en el paso del mismo nombre buscaron evidencias que nos permitieran afirmar el supuesto trajinar de las huestes españolas de Diego de Almagro en 1536 y comprobar en este trayecto el tránsito y los sitios utilizados en la época inca. Reconocimos un sitio de ese último tiempo, a unos $6 \mathrm{~km}$ aguas arriba de la desembocadura del arroyo, donde la implantación inca se hizo sobre una preexistente elaborada con pircas del tipo parapetos, las que fueron modificadas y, en algunos casos, transformadas en kancha o RPC. Luego de estas ocupaciones, la evidencia muestra superposiciones de materiales de los arrieros del siglo xix y principios del $\mathrm{xx}$, sin evidencia intermedia, como podría haber sido la del pretendido pasaje de Almagro. También hallamos otro sitio, de mayor envergadura, desarrollado en unas 13 há en el entorno de un cerro bajo, igualmente próximo al arroyo Comecaballos y al emplazamiento de la referida casucha para arrieros, a unos $15 \mathrm{~km}$ de la desembocadura (fig. 4).

Este establecimiento, al cual las poblaciones locales acudirían estacionalmente, ofrece estructuras pircadas, principalmente circulares, al modo de los parapetos, una piedra parada -quizás un menhir pequeño- en la explanada del cerro, junto a indicios de otras construcciones en pirca, así como estructuras modificadas probablemente en época inca.

La cerámica del sitio apunta a las poblaciones regionales del Formativo o del Período de Integración, con alguna evidencia de cerámica inca, cuya cronología corresponde a la primera mitad del siglo xvi. La evidencia de tiestos fragmentados es preexistente y remonta a unos siglos antes (tabla 1). ${ }^{3}$

Prospectamos la quebrada por ambas márgenes del arroyo Comecaballos hasta el hito del paso homónimo, a unos 4500 msnm (S28 10' 54.2", W69 22' 23.5”, 4.519 msnm, según GPS). Las prospecciones entre Comecaballos 1 y 2 , y luego hasta alcanzar el paso a $4500 \mathrm{msnm}$, nos permitieron reconocer allí una tumba y, al menos, otros siete montículos de piedra, cuyas dimensiones van de $0,80 \times 2,5 \mathrm{~m}$ a $2 \times 7 \mathrm{~m}$, semejantes a las estructuras que suelen marcar tumbas sumarias. Constatamos, además, que el ascenso al paso está jalonado por cornamentas de bovinos, atribuibles a los mencionados arreos.

De la excavación de algunos de esos montículos obtuvimos evidencias en general y de entierros en particular, con la salvedad de uno, situado a unos 300 $\mathrm{m}$ al sur del paso (límite internacional), que albergaba buena parte de un esqueleto juvenil. Si bien hallamos algunas piezas dentales, no encontramos el cráneo. El esqueleto se encontraba en posición decúbito ventral, con los brazos cruzados por delante y una pierna sobre la otra. La ubicación puede responder, más que a una cuestión cultural, a la postura natural de protección ante las rigurosas condiciones climáticas de altura que implicaron finalmente la muerte del joven (fig. 5).

El esqueleto de la tumba del paso tiene vestigios de vestimenta de arriero y la datación C14 lo coloca en el intervalo de los últimos 200 años $^{4}$. Por su parte, 

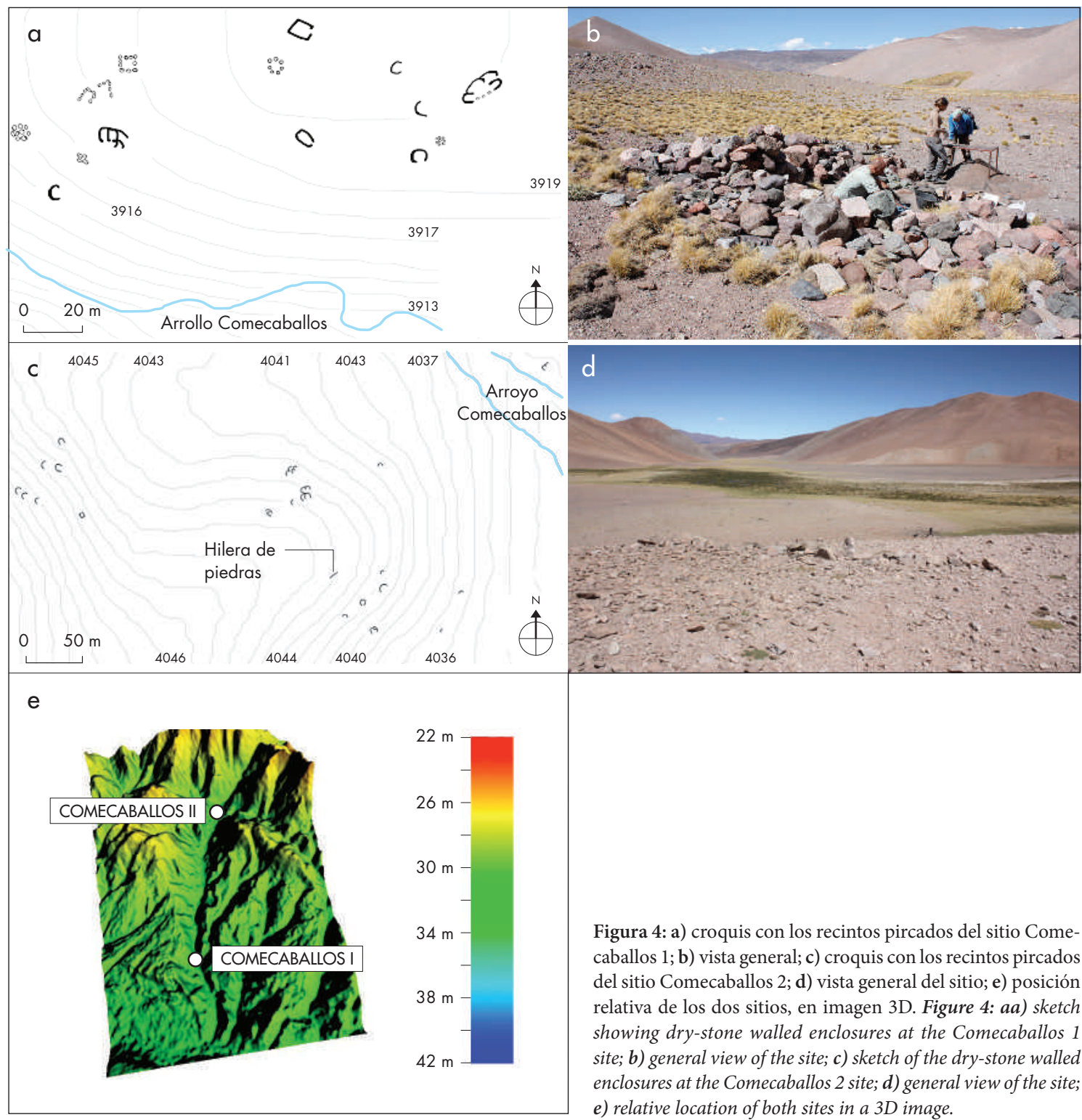

d

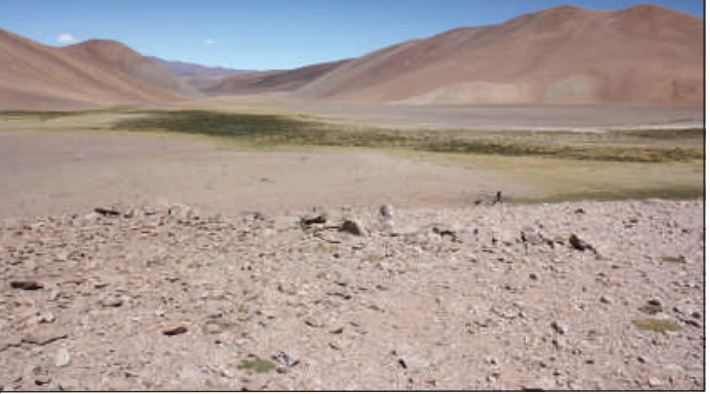

Figura 4: a) croquis con los recintos pircados del sitio Comecaballos $1 ; \mathbf{b}$ ) vista general; c) croquis con los recintos pircados del sitio Comecaballos 2; d) vista general del sitio; e) posición relativa de los dos sitios, en imagen 3D. Figure 4: aa) sketch showing dry-stone walled enclosures at the Comecaballos 1 site; $\boldsymbol{b})$ general view of the site; $\boldsymbol{c})$ sketch of the dry-stone walled enclosures at the Comecaballos 2 site; $d$ ) general view of the site; e) relative location of both sites in a $3 D$ image.

la datación C14 de los restos de la subida al paso los colocó en el siglo IX AD (tabla 2).

\section{La Quebrada y Pasos de Peña Negra y de La Ollita}

La quebrada por la que se remonta el arroyo Peña Negra cuenta con numerosos parapetos y conjuntos de estructuras pircadas. Las hemos relevado y, en algunos casos, datado su cerámica (tabla 1), lo que orienta hacia momentos Formativos Tardíos y a los Desarrollos Regionales. Se observa presencia de cerámica de influencia inca, como el Diaguita de la Fase III de aculturación inca o el Inca Provincial. No hemos reconocido elementos coloniales, salvo por nuestra interpretación de los grabados de cruces, sitos en una roca granítica aislada, en la margen derecha del curso del arroyo. La roca incluye, además, motivos claramente indígenas. Según nuestro parecer, la impronta de las cruces es colonial. Según la interpretación de algunos colegas 

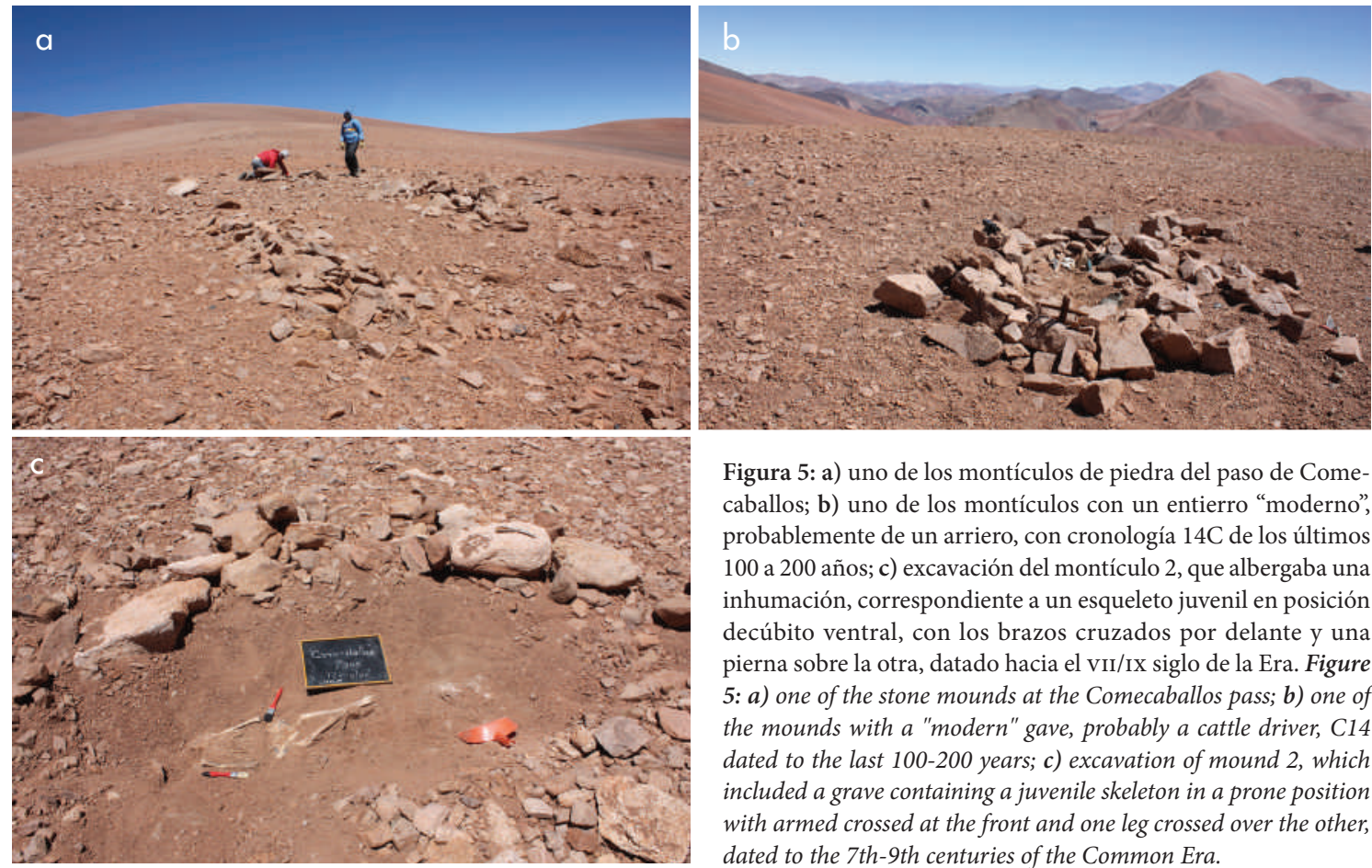

Figura 5: a) uno de los montículos de piedra del paso de Comecaballos; b) uno de los montículos con un entierro "moderno", probablemente de un arriero, con cronología $14 \mathrm{C}$ de los últimos 100 a 200 años; c) excavación del montículo 2, que albergaba una inhumación, correspondiente a un esqueleto juvenil en posición decúbito ventral, con los brazos cruzados por delante y una pierna sobre la otra, datado hacia el VII/IX siglo de la Era. Figure 5: $\boldsymbol{a})$ one of the stone mounds at the Comecaballos pass; $\boldsymbol{b}$ ) one of the mounds with a "modern" gave, probably a cattle driver, C14 dated to the last 100-200 years; c) excavation of mound 2, which included a grave containing a juvenile skeleton in a prone position with armed crossed at the front and one leg crossed over the other, dated to the 7th-9th centuries of the Common Era.

Tabla 1. Dataciones de cerámica de sitios de las quebradas y pasos cordilleranos del oeste de La Rioja y noroeste de San Juan, entre los pasajes trasandinos de Pircas Negras y Peña Negra, y el río de la Paila (Barrancas Viejas, Comecaballos/Barrancas Blancas, La Ollita). Prospecciones y excavaciones: J. Roberto Bárcena. Table 1. Ceramic datings of sites in ravines and mountain passes in western La Rioja and northwestern San Juan, between the Andean mountain passes of Pircas Negras and Peña Negra, and the De la Paila river (Barrancas Viejas, Comecaballos/Barrancas Blancas, La Ollita). Prospections and excavations: J. Roberto Bárcena.

\begin{tabular}{|c|c|c|c|c|c|c|}
\hline MUESTRA ${ }^{*}$ & $\mathrm{~N}^{\circ}$ & DESCRIPCIÓN & P (Gy) & D (Gy/año) & $\begin{array}{l}\text { EDAD } \\
(\text { años AP)** }\end{array}$ & FECHA \\
\hline UCTL 2033 & 1 & Cerámica inka, sitio del paso Pircas Negras. & $2,03 \pm 0,17$ & $4,86^{*} 10-3$ & $420 \pm 40$ & $1585 \mathrm{DC}$ \\
\hline UCTL 2034 & 2 & Cerámica inka, sitio del paso Peñas Negras. & $2,70 \pm 0,27$ & $4,87^{\star} 10-3$ & $555 \pm 55$ & $1455 \mathrm{DC}$ \\
\hline UCTL 2035 & 3 & $\begin{array}{l}\text { Cerámica inka del sitio Tambo Minero, margen izquierda } \\
\text { arroyo afluente del Peñas Negras. }\end{array}$ & $1,95 \pm 0,20$ & $4,67^{*} 10-3$ & $415 \pm 40$ & $1590 \mathrm{DC}$ \\
\hline UCTL 2036 & 4 & $\begin{array}{l}\text { Cerámica del Período Inka, sitio margen izquierda } \\
\qquad \mathrm{A}^{\circ} \text { Peñas Negras. }\end{array}$ & $1,83 \pm 0,14$ & $4,75^{\star} 10-3$ & $385 \pm 40$ & $1620 \mathrm{DC}$ \\
\hline UCTL 2037 & 5 & Cerámica inka del tambo Río de la Paila. & $1,70 \pm 0,17$ & $3,94^{*} 10-3$ & $430 \pm 40$ & $1575 \mathrm{DC}$ \\
\hline UCTL 2038 & 6 & $\begin{array}{l}\text { Cerámica inka de excavación del sitio Comecaballos } 1, \\
\text { recinto LL 1.1, } 10 \text { a } 20 \mathrm{~cm} .\end{array}$ & $2,01 \pm 0,18$ & $5,11^{*} 10-3$ & $395 \pm 40$ & $1610 \mathrm{DC}$ \\
\hline UCTL 2039 & 7 & $\begin{array}{c}\text { Cerámica de la etapa agro alfarera regional. Sitio SA2 } \\
\text { margen derecha } \mathrm{A}^{\circ} \text { Peña Negra. }\end{array}$ & $5,05 \pm 0,51$ & $4,78^{\star} 10-3$ & $1055 \pm 100$ & $950 \mathrm{DC}$ \\
\hline UCTL 2040 & 8 & Cerámica del Período Inka. Sitio Comecaballos 1, superficie. & $1,65 \pm 0,14$ & $4,87^{\star} 10-3$ & $340 \pm 40$ & $1665 \mathrm{DC}$ \\
\hline UCTL 2041 & 9 & Cerámica del Período Inka. Sitio Comecaballos 2, superficie. & $2,19 \pm 0,21$ & $4,88^{\star} 10-3$ & $450 \pm 45$ & $1555 \mathrm{DC}$ \\
\hline UCTL 2042 & 10 & Cerámica vidriada, hechura de torno. Sitio del Período Inka, & $2,05 \pm 0,16$ & $4,98^{*} 10-3$ & $410 \pm 40$ & $1595 \mathrm{DC}$ \\
\hline UCTL 2043 & 11 & $\begin{array}{l}\text { Tambo de Confluencia, del Aº Peña Negra con el río Blanco. } \\
\text { Cerámica inka del tambo Río de la Paila. }\end{array}$ & $2,27 \pm 0,20$ & $5,26^{*} 10-3$ & $430 \pm 40$ & 1575 DC \\
\hline
\end{tabular}

* Pontificia Universidad Católica de Chile, Facultad de Física, Laboratorio de Dosimetría. / ** Año base: 2005. 
Tabla 2. Dataciones 14C de Comecaballos I y paso de Comecaballos. Table 2. C14 datings of Comecaballos I and paso de Comecaballos.

\begin{tabular}{c|c|c|c|c|c|c}
\hline LAB & $N^{\circ}$ & MUESTRA & MATERIAL & RESULTADO AP & CAL. AP & CAL. AD \\
\hline Beta & 297637 AMs & $\begin{array}{c}\text { CCPasoE2 } \\
\text { Entierro de la } \\
\text { subida al paso }\end{array}$ & Colágeno óseo & $1250 \pm 30$ & 1270 a 1080 & 680 a 870 \\
\hline Beta & 261730 & PCC1LL3.110 & Carbón & $140 \pm 40$ & 290 a 0 & 1660 a 1960 \\
\hline Latyr & 2516 & $\begin{array}{c}\text { CCEPasol } \\
\text { Entierro del paso }\end{array}$ & Piel humana & "moderno" & 0 a 200 &
\end{tabular}

serían propias de arrieros del siglo XIX/xx (Revuelta 2007-2008: 10) (fig. 6). ${ }^{5}$

En la profusión de sitios de las márgenes del río o arroyo de la Peña Negra destacan otros dos tambos (Tambo II y iII de la Peña Negra, según nuestra denominación) ¿construidos? sobre impronta de recintos pircados circulares y parapetos preexistentes (fig. 7).

La quebrada de Peña Negra, jalonada por las estructuras señaladas, alcanza la confluencia de un arroyo que viene del oeste y desemboca en la misma. Lo hemos llamado Cerro Verde. Se encuentra allí un tambo de escala media, de acuerdo a los términos que venimos tratando. Lo hemos denominado tambo minero, ya que sobre él se han instalado actualmente galpones y casetas habitables de una compañía de exploración minera en un cerro que lo enmarca por el norte. El tambo reúne en su arquitectura códigos de la planta característica inca regional, en su caso incipientes RPC. Se incluyen parapetos y construcciones circulares de pirca, que ofrecen materiales de época inca, como los de los tipos cerámicos ya enunciados, incluidos los de poblaciones locales/regionales. En los niveles superiores excavados se suman elementos usados por los arrieros del XIX-Xx, denotando al conjunto una plataforma, seguramente ceremonial, sita en la falda del cerro por encima de las otras construcciones y delimitada por grandes piedras escogidas y trabajadas (fig. 8).

Tambo minero se desarrolla en unas 6 há y los espacios delimitados por pirca, que pudieron ser techados o no, alcanzan los $2000 \mathrm{~m}^{2}$.

Por el arroyo Cerro Verde se puede avanzar al oeste/suroeste para alcanzar el cerro El Potro, o bien, al oeste/noroeste para alcanzar el paso de La Ollita o sus desechos. Si se sigue desde su desembocadura en el Peña Negra hacia el norte/noroeste se puede acceder primero a la quebrada, arroyo y paso de La Ollita, zona bajo exploración minera actual. Además de los conspicuos parapetos pircados más o menos aislados y ubicados principalmente en la margen derecha y en la llanura de inundación del curso hídrico, se halla el tambo de La Ollita, que reúne características de la clásica arquitectura inca regional, con varios RPC ubicados en tres sectores, en la margen derecha del arroyo La Ollita (fig. 9).

Los que denominamos Sector II y Sector III, más australes del tambo, están separados del Sector I, más nórdico, por una elevación. Se trata de un promontorio alargado en el sentido suroeste/noreste, que impide una visión directa entre los sectores, la que se logra desde una estructura aislada, sita en el flanco del cerro que enmarca el tambo por el oeste.

$\mathrm{Al}$ avanzar por la margen derecha del arroyo La Ollita se alcanza una vega de relativa extensión situada próxima al tambo, con agua acumulada, de cierta profundidad. A $1,7 \mathrm{~km}$ al noroeste del Sector I y al pie del paso de la Ollita, se encuentra otra vega y un conjunto de construcciones pircadas, aglomeradas, del estilo de los parapetos y recintos circulares. Se trata seguramente de locaciones temporales de las poblaciones locales/regionales, reutilizadas en época inca, como lo demuestra la presencia de cerámica de los tipos locales y la del inca provincial o del diaguita de la Fase iII de aculturación por la organización estatal.

El sector que denominamos del ushnu se extiende por unos $3000 \mathrm{~m}^{2}$, siguiendo luego hacia el sureste el sector I unos $5000 \mathrm{~m}^{2}$, el II en unos $3200 \mathrm{~m}^{2}$ y el III en aproximadamente $200 \mathrm{~m}^{2}$. Desde esta última posición, a unos $6,5 \mathrm{~km}$ de distancia, se ubica el tambo minero. 
Tabla 3. Dataciones C14 del paso de La Ollita. Table 3. C14 datings of paso de La Ollita.

\begin{tabular}{|c|c|c|c|}
\hline MUESTRA & DESCRIPCIÓN & EDAD (AÑOS AP) & FECHA AD SEGÚN INTERVALO DE CALIBRACIÓN \\
\hline $\begin{array}{c}\text { LP- } 2804 \\
\text { Carbón de fogón }\end{array}$ & $\begin{array}{c}\text { La Ollita } \\
\text { SIIR1H2S31020 }\end{array}$ & $\begin{array}{c}530 \pm 50 \\
(1420 \pm 50 \mathrm{AD})\end{array}$ & $1408-1449$ \\
\end{tabular}

Tabla 4. Dataciones 14C de Comecaballos I y paso de Comecaballos. Table 4. C14 datings of Comecaballos I and paso de Comecaballos.

\begin{tabular}{c|c|c|c}
\multirow{2}{*}{ MUESTRA } & DESCRIPCIÓN & EDAD (AÑOS AP = 2010 AD) & FECHA AD \\
\hline UCTL 2295 & LOPG1 (cerámica gris) & $595 \pm 60$ & 1415 \\
\hline UCTL 2296 & LOPR2 (cerámica inka) & $540 \pm 50$ & 1470
\end{tabular}
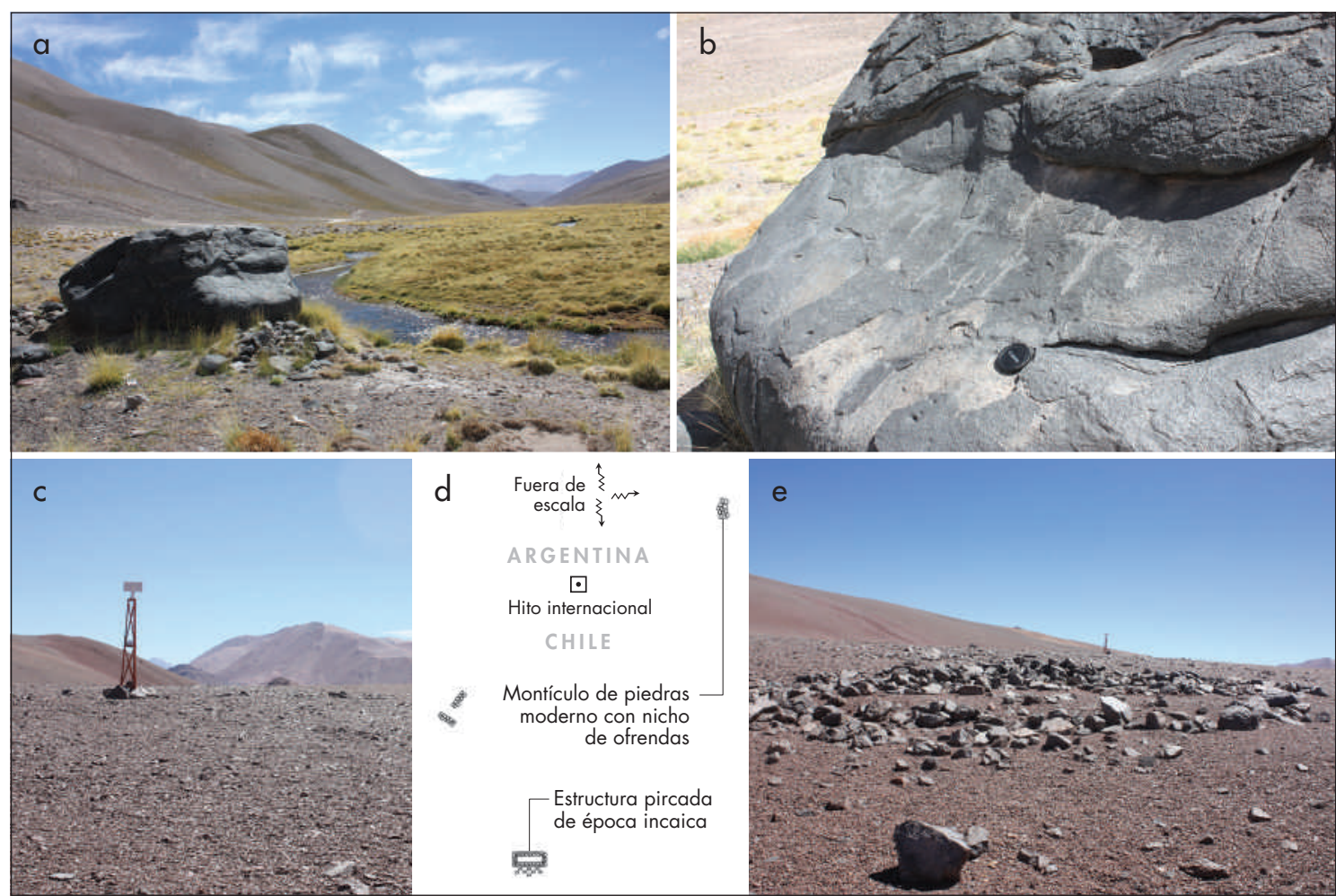

Figura 6: a) vista de la roca de la margen derecha del arroyo Peña Negra, que alberga grabados indígenas, coloniales y modernos; b) detalle de los grabados de "cruces" que reputamos de época colonial temprana; c) vista del paso de Peña Negra; d) croquis de las estructuras pircadas del paso de Peña Negra; e) vista de la estructura principal, de época inca. Figure 6: a) view of the rock on the right side of the Peña Negra creek, harboring indigenous, colonial and modern engravings; $\boldsymbol{b}$ ) detail of the the engravings of "crosses" that we consider to be from the early colonial period; $c$ ) view of the Peña Negra mountain pass; $d$ ) sketch of the dry-stone boundary structures of the paso de Peña Negra; $\boldsymbol{e})$ view of the main structure, from the Inca Period. 

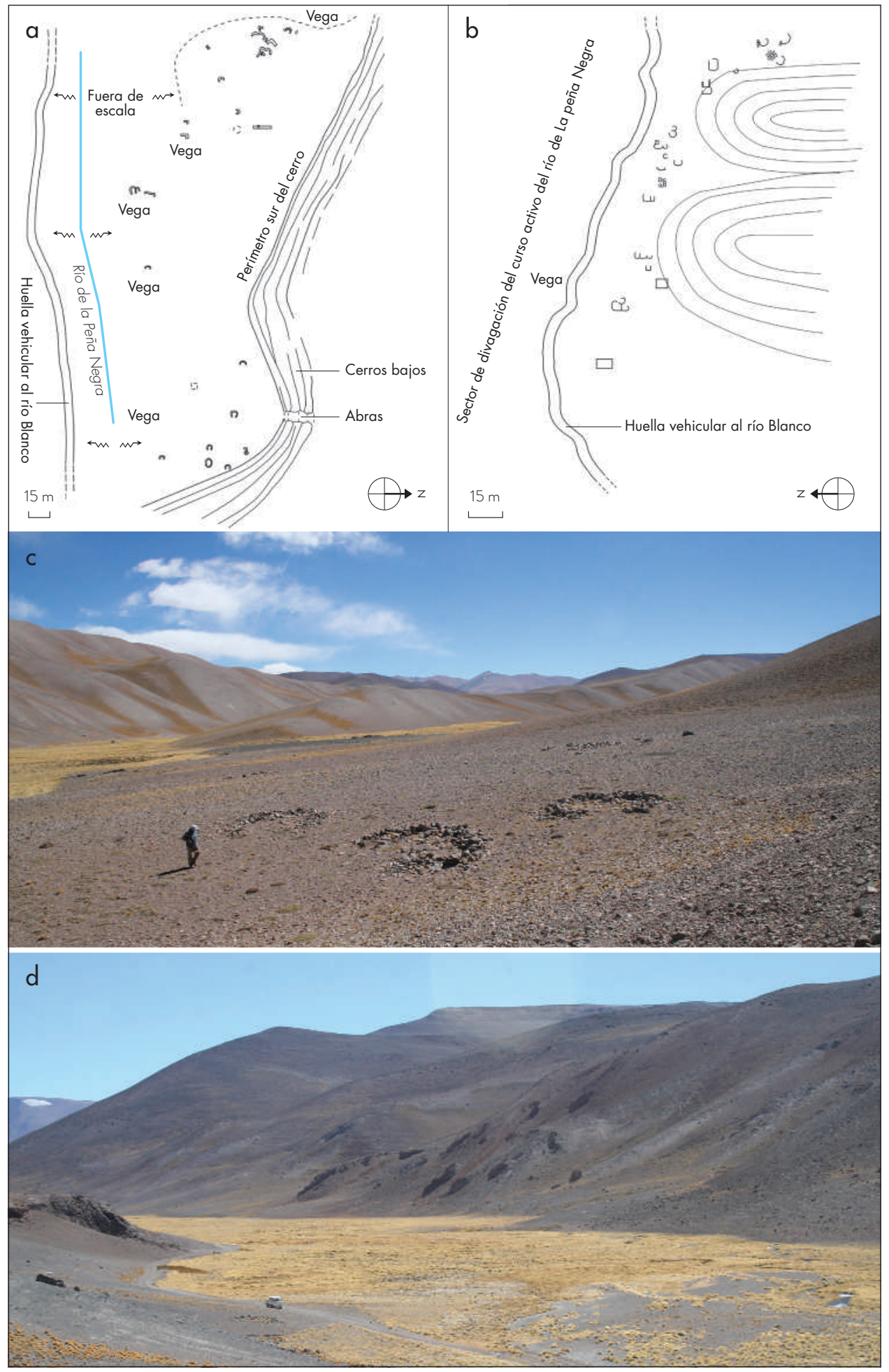

Figura 7: a) croquis de planta de los sitios que denominamos Tambo iI y Tambo III del arroyo Peña Negra, de impronta arquitectónica regional con modificaciones inca; b) imágenes de los Tambos II y III. Figure 7: a) sketch of the sites we have called Tambo II and Tambo III in Peña Negra creek, of regional architectonic style with Inca modifications; $\boldsymbol{b}$ ) images of Tambo II and Tambo III. 


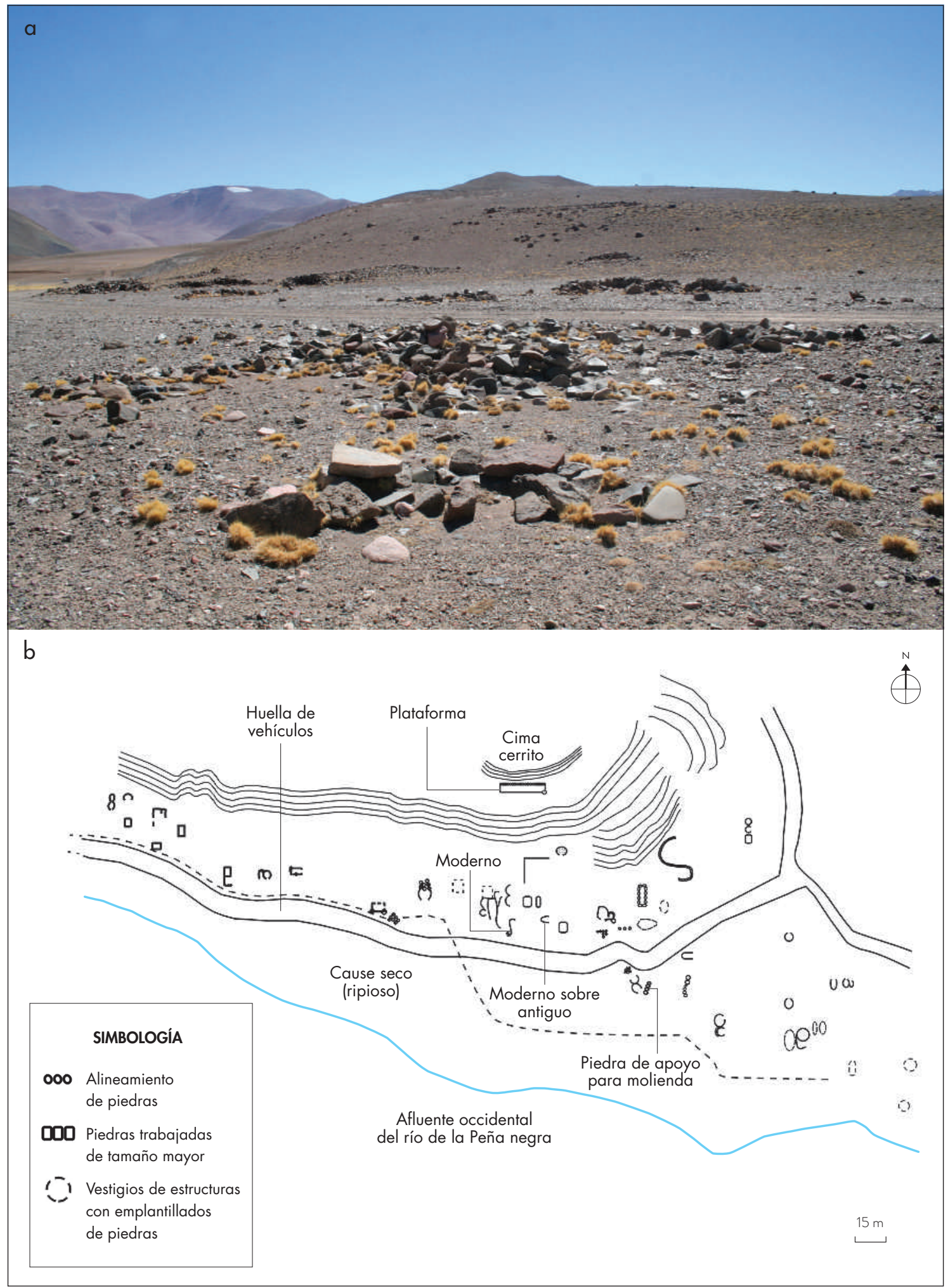

Figura 8: a) croquis de planta de tambo minero; b) vista general del sitio. Figure 8: $\boldsymbol{a}$ ) sketch of tambo minero; $\boldsymbol{b}$ ) general view of the site. 

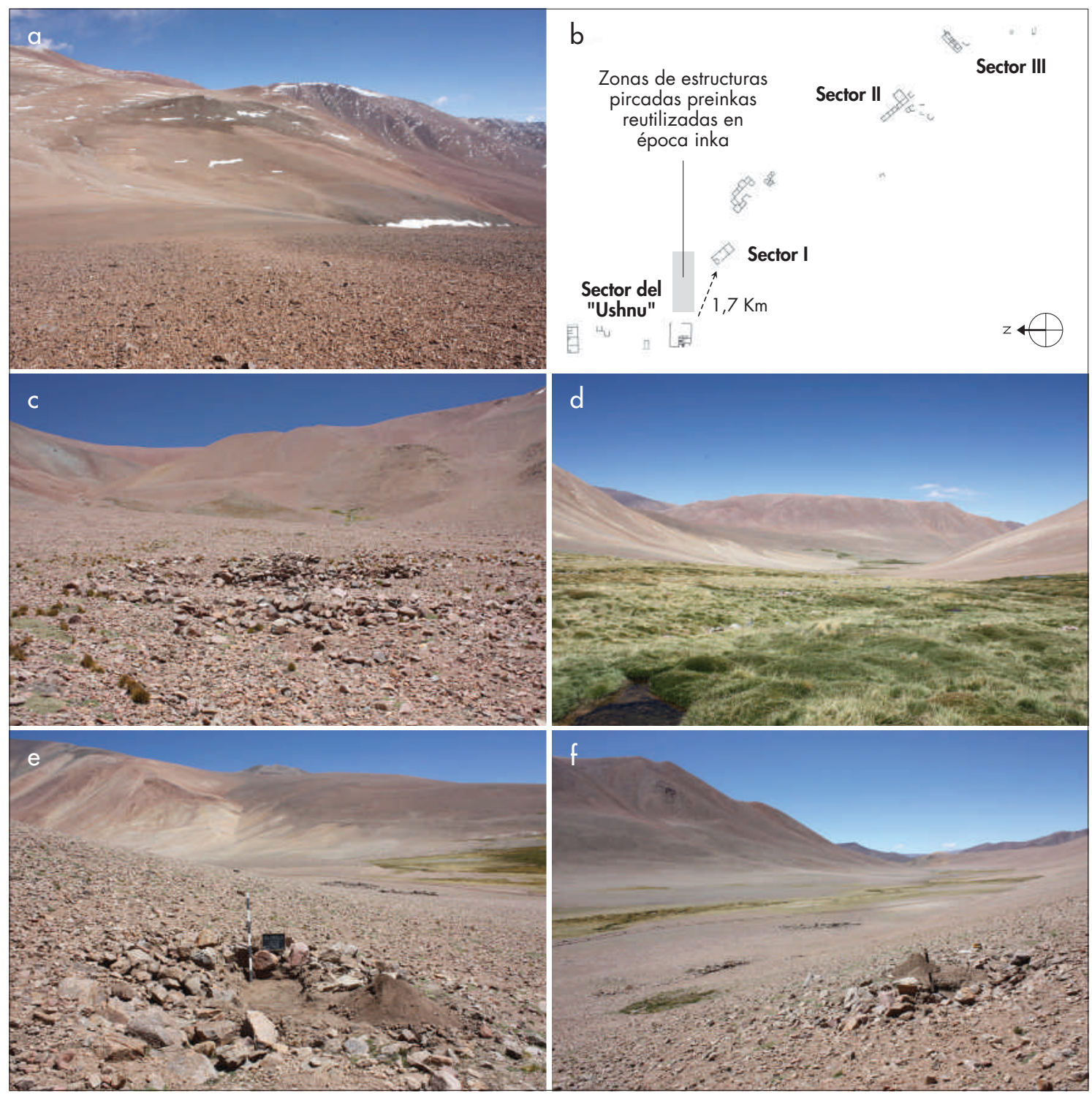

Figura 9: a) vista general del área del paso de La Ollita; b) croquis de planta del Tambo La Ollita; c) imágenes de las vegas y Tambo La Ollita (Sector 1, Sector 2, "Ushnu"). Figure 9: a) general view of area around paso de La Ollita area; $\boldsymbol{b}$ ) sketch of Tambo La Ollita; $\boldsymbol{c}$ ) images of the vegas and Tambo La Ollita (Sector 1, Sector 2, "Ushnu").

La superficie total del tambo de La Ollita, encerrada entre pircas, alcanza los $1400 \mathrm{~m}^{2}$ (véanse las tablas $3 \mathrm{y}$ 4 para conocer las dataciones C14 - nivel de ocupación inca-y TL-sobre cerámica inca, con motivo pintado de negro sobre engobe rojo-, respectivamente).

Las últimas estructuras del tambo de La Ollita hacia occidente se encuentran ya en los comienzos de la hoyada de ascensión al paso. Este sector supera los $4300 \mathrm{msnm}$ y el puerto propiamente tal los $4700 \mathrm{msnm}$.
Notable es un conjunto arquitectónico al pie de la hoyada de ascensión al paso. Consiste en estructuras pircadas donde colegimos una escalinata de pocos peldaños que une por sus desniveles, siguiendo los de la declinación de la hoyada, recintos menores superiores con uno mayor más bajo, del tipo patio o reducida plaza. Esto nos ha hecho pensar que están asociadas a plataformas ceremoniales que admiten parangón con una clase de ushnu. 
Próximas a esta estructura se encuentran algunas menores y otra mayor, del tipo de los recintos rectangulares cruzados con paredes transversales, divisorias internas, que delimitan espacios como patios, a los que se comunican algunos recintos adosados a las paredes de mayor longitud. El tipo arquitectónico es característico de muchos tambos del noroeste y, particularmente, del centro oeste argentino, aunque en este caso las piedras que lo conforman tienen un poco más de envergadura.

El área se completa con un sector que estimamos de cantera, con ubicación relacionada con los Sectores I y II, donde se aprecian remanentes del trabajo de la piedra, cuyo canteado se ve en ejemplares de las paredes de los recintos.

El tambo de La Ollita destaca en el conjunto de los ubicados al oeste de Laguna Brava y de los relacionados con los pasos entre Pircas Negras por el norte y La Ollita por el sur por su impronta arquitectónica y relativa complejidad. Por otra parte, este paso del sur, de mayor altura que los otros tratados aquí -ronda los 4700-4800 msnm- y que cuenta con cierta dificultad de ascenso por la hoyada, tiene la particularidad de "caer" más directamente a los cursos fluviales cuyas quebradas finalmente avanzan sobre el curso principal que lleva a Copiapó. ${ }^{6}$

\section{DISCUSIÓN}

\section{Desde la perspectiva arqueológica}

Desde los sitios chilenos de la quebrada y el arroyo de La Ollita se avanza hacia el río Ramadillas, del cual La Ollita es afluente. Este río avanza en dirección noroeste desembocando en el río Vizcachas del Pulido el que, a su vez, tomando rumbo suroeste alcanza al río Pulido en el sector de formación de éste en las Juntas del Potro, próximo al complejo yacimiento local e inca de Iglesia Colorada. El Pulido sigue con sentido noroeste hasta alcanzar La Junta con el río Jorquera, encontrándose con el río Manflas, contribuyendo a formar el río Copiapó. Aguas abajo se halla el notable sitio inca y establecimiento metalúrgico de Viñas del cerro que, con dirección nortenoroeste, lleva a Copiapó.

Entre La Ollita y Pircas Negras, el primer paso nombrado es el que orienta más directamente la trayectoria hacia Copiapó, pues los pasos de Peña Negra -cae al río Cachitos-, Comecaballos -cae al arroyo homónimo y al Río Turbio- y Pircas Negras -cae a la quebrada Pircas Negras y al Río Turbio-, y sus desechos, llevan a quebradas/cursos que están más al norte e implicarían trayectos menos prácticos para alcanzar el mismo camino a Copiapó.

La posición de La Ollita como paso practicable, aunque más alto que los otros mencionados, implica el camino más corto desde el oriente de los Andes en esa latitud para alcanzar el área de Iglesia Colorada y con ella el camino a Copiapó. Esto había sido ya señalado: "Sin duda la ruta más breve para alcanzar la vertiente oriental de la cordillera andina a partir de Iglesia Colorada es la del paso de La Ollita" (Niemeyer 1986: 192). Por el lado chileno del paso de La Ollita se han señalado tambos que, sin duda, jalonaban uno de los caminos con orientación más directa a Copiapó, como son el de La Ollita A y La Ollita B.

Debemos principalmente a Niemeyer (1986) y a Niemeyer et al. (1997), entre otros, la descripción del área y de los sitios significativos de la misma. Fue él quien, con los apoyos pertinentes, recorrió el sector registrándolo con la acuciosidad del arqueólogo. A él se debe la descripción de los mencionados tambos, los que probablemente sean los mismos que Raffino (2004: $59,60,62,66)^{7}$ menciona en su propuesta del paso andino por Diego de Almagro, aunque lo hace pasar principalmente por Peña Negra/Comecaballos (Raffino 1995: 40; 2004: 48, 59).

En la subida occidental de los Andes por el río La Ollita, Niemeyer (1986: 192) reconoce un grupo de pircas circulares al margen de una vega, conjunto que denomina Tambería B, mientras que más arriba, en relación con una vega más extensa, y a $3500 \mathrm{msnm}$, encuentra

[...] un poblado bastante extenso compuesto en su parte principal por recintos circulares aislados o aglutinados en dos o tres unidades; pero también hay unidades de planta mucho más complejas en las cuales se combinan recintos circulares con recintos rectangulares y con patios o corrales. Este último conjunto lo hemos denominado TAMBERÍA [sic] A [...]" (Niemeyer 1986: 198), para continuar después diciendo que "[...] En la Tambería A, marginalmente a los recintos y la vera de la vega se conserva un sector de un camino de 2.5 a 3,0 m de ancho que se encuentra emplantillado con piedras lajas. Sin duda es parte del camino de origen incaico, que permitía la comunicación más breve entre el valle del río Copiapó y La Rioja, en Argentina" (Niemeyer 1986: 198).

Prosigue luego indicando que próximo al paso de 4700 msnm halla: "un edificio en ruinas, de paredes altas, 
pircadas, de piedras bien calzadas" (Niemeyer 1986: 198) que estima estaba sin uso y en construcción. El paso consiste en un par de unidades conexas, que son de planta rectangular, de 7 × 12 m; se halló también al pie del paso cerámica diaguita de influencia inca (1986: 198-199). Para Niemeyer (1986: 200), el conjunto de La Ollita destaca por la relativa envergadura de sus construcciones (al menos $720 \mathrm{~m}^{2}$ sumando Tambería A -500 $\mathrm{m}^{2}$ - y Tambería B -220 $\mathrm{m}^{2}$-) en comparación con los pasos cercanos, a lo que hay que agregar que es el paso más directo hacia Copiapó, aunque presenta la dificultad de retener nieve hasta diciembre. ${ }^{8}$

La cerámica de superficie de las Tamberías (А у в) de La Ollita suma a los tipos local/regionales la propia del diaguita de aculturación inca (Niemeyer 1986).

La comprobación de Niemeyer coincide con la nuestra en cuanto a la envergadura de la infraestructura inca, propia o modificada de la preexistente, en los pasos de La Ollita, Peña Negra, Comecaballos y Pircas Negras, destacando en el lado argentino de los Andes las construcciones de La Ollita, cuyas plantas son claramente inca desde el arranque, al menos en los sectores I y II, y en el sector que denominamos del ushnu.

En Bárcena (2007) puede seguirse la infraestructura que reconocimos en los pasos mencionados (especialmente Peña Negra y Pircas Negras, cuya descripción no se reitera aquí), contrastándola con la trasandina reconocida por Niemeyer (1986) en el último tramo de esos pasos ${ }^{9}$, concluyéndose sobre los itinerarios trasandinos con la más calificada impronta inca y con respecto a la mayor escala de la misma.

Si sumamos la proliferación de asentamientos con mayor o menor impronta inca y su relativa envergadura -comenzando con el tambo de Confluencia, en la encrucijada del arroyo Peña Negra y el río Blanco, remontando la quebrada Peña Negra y continuando por los tambos y conglomerados de parapetos y las construcciones de recintos circulares que ya enunciamos- apreciamos que la logística de instalaciones es más estructurada y alcanza mayor envergadura en el derrotero que lleva al Tambo y paso de La Ollita, que en el correspondiente al propio paso de Peña Negra o de sus desechos. Lo mismo ocurre con respecto al de Comecaballos y el de Pircas Negras. En los últimos es Comecaballos el que denota sendos sitios, a unos $21 \mathrm{~km}$ y a $15 \mathrm{~km}$ del paso. Uno de ellos, Comecaballos 1, aunque tiene alguna impronta arquitectónica inca y cerámica del período, no llega a 500 $\mathrm{m}^{2}$ de superficie construida pasible de techarse, mientras que el otro, Comecaballos 2, si bien se desarrolla en un espacio de envergadura, ofrece estructuras con pircados simples, elementales, prácticamente sin impronta inca y con poca cerámica del período, alcanzando la superficie encerrada entre pircas y pasible de techumbre solo unos $700 \mathrm{~m}^{2}$. La mayor parte de la evidencia de este último sitio remite a tiempos pre-inca o bien al uso del paso por los arrieros de los siglos XIX y xx.

\section{Desde la perspectiva histórica}

\section{Los pasos cordilleranos que pudo utilizar Almagro según las fuentes coloniales}

No sería menor en la planificación del viaje de Almagro la incidencia del Inca Paullu que debió allegar el conocimiento, no solo de las vías de comunicación en uso por la organización estatal, sino la de los ámbitos para procurar agua, alimento y alojamiento. El propio Paullu debía pasar los trabajos del conjunto de la expedición, por lo que suponemos que procuraría los más aptos pasajes de los que tuvieran conocimiento. ${ }^{10}$

Por más que llevaran tiendas de campaña y fueran muchas las personas y equipos que se desplazaban, a las necesidades de la despensa, de aguadas y pastos para las cabalgaduras y otros animales, se sumaría aprovechar al máximo los alojamientos con que pudiera contarse. Al menos los utilizarían el escogido grupo de vanguardia de Almagro y compañeros. Máxime si se trataba de los existentes en las quebradas de acceso a los pasos de altura y en las proximidades de estos mismos.

En este sentido, está clara la importancia del servicio de tambos en el itinerario que refiere Matienzo (1987 [1556]), que fue el de Almagro y de Rojas, como asimismo se repiten los cronistas para mencionar poblados del recorrido de Almagro o las paradas de este mismo en aposentos del camino, en tambillos o refugios parecidos, entre otras menciones a estos recintos y a personas que los usan (v.g.: Molina 1968 [1552]: 85; Cieza de León 1909 [1553]: cap. xCv; Herrera 1901 [1601-1615]: 488; entre otros).

Si esto es así, y se descarta que desde "Talombones/ la Ciénaga"-"Londres/El Shincal”, como colegimos del itinerario de Matienzo (1987 [1556]), se vire al noroeste para alcanzar el alto paso de San Francisco y más lejano con respecto al Copayapo, desde Watungasta o donde fuere en sus cercanías, debemos aceptar que lo más práctico es el camino al oeste y a los pasos entre Peñasco de Diego/ 
Pircas Negras y los intermedios Comecaballos/Barrancas Blancas, Peña Negra y su desecho, hasta La Ollita.

De estos pasos, la aproximación inmediata a Pircas Negras se parece más a la especie de páramo/"llanada" de dos leguas que se señala en crónicas, mientras que Comecaballos es relativamente más accesible, aunque no cuenta con infraestructura inca de relieve, siendo la quebrada del arroyo Peña Negra, partiendo de Confluencia, la mejor equipada en cuanto infraestructura arquitectónica aún en uso en época inca. Nos encontramos así con la más clara impronta de ese tipo en La Ollita, que alcanza el pie del paso homónimo y es precedida, a unos seis kilómetros de distancia, por la instalación de tambo minero. Suman estas dos, por ejemplo, unos $3200 \mathrm{~m}^{2}$ pasibles de considerarse superficie cubierta, la que aumenta bastante con la del recorrido por la quebrada de Peña Negra y con las de las instalaciones que señala Niemeyer (1986) allende los Andes $\left(770 \mathrm{~m}^{2}\right.$ de las Tamberías A y B), en contraste con unos $1100 \mathrm{~m}^{2}$ de instalaciones de la Quebrada y paso de Comecaballos (fig. 10).

Por otra parte, tal como lo hemos señalado, La Ollita es el paso por el que se accede más directamente hacia Copiapó, alcanzándose primero Iglesia Colorada/ Choliguín, que debió ser el lugar de refacción del grupo de Almagro y los que le siguieron en su bajada de los Andes, como lo plantearon otros colegas (Advis 1994; Cervellino 1994; Niemeyer et al. 1997: 252) y hemos señalado en este artículo.

Los actuales topónimos Comecaballos y Peñasco de Diego mueven a comparaciones con hechos que señalan las fuentes coloniales inclinando hacia ellos las posibilidades del paso de Almagro. Aunque probablemente debiéramos plantearnos primero desde cuándo se utilizan esas denominaciones geográficas y si responden a una antigua tradición local y las circunstancias de su surgimiento, cuestión que puede no corresponderse con el efectivo paso de Almagro.

Lo que hemos señalado nos lleva a considerar las fuentes que están en el origen de las propuestas de los autores modernos sobre el lugar de paso de Almagro. Nos encontramos con que las atribuidas a dos clérigos de la expedición de Almagro y por tanto testigos del viaje, que refiere a acontecimientos de Perú hasta 1552 AD (Cristóbal de Molina -el chileno o el Almagrista- y Bartolomé de Segovia) dicen poco del pasaje de la cordillera de los Andes, aunque se enfatiza: "He apuntado esto que vi con mis ojos y en que por mis pecados anduve", describiendo que avanzan "por el camino real del Inga, que iba derecho a las provincias de Chile”. Luego agrega Molina:

y de allí partieron a la provincia de Chicoana; que es de los Diaguitas [...] Aquí vino al Adelantado un capitán con cincuenta hombres casi todos de caballo y desde aquí a las provincias de Copiapó, que es en la costa del Sur, hay casi ciento y cincuenta leguas de despoblado, las cuales el Adelantado y su campo pasó con harto trabajo, porque le faltó el mantenimiento y no hallaba pueblos donde poder reparar y si algunos hallaban eran muy pequeños y no tenían para comer aun de presente. Pasó el Adelantado y su gente, para pasar a los valles de Copiapó, un despoblado y puerto de trece jornadas, que cuando es tiempo de nieves es todo el camino nevado a la rodilla donde menos hay nieve, y cuando no la hay, que era cuando pasó el Adelantado, hace tan gran frío que se murieron en una noche en el puerto, que es cinco jornadas de Copiapó, setenta caballos y gran cantidad de piezas de servicio de los naturales, de frío, y con este trabajo llegó al primer valle de Copiapó (Molina 1968 [1552]: 85).

Francisco López de Gomara, quien no estuvo en América y escribe por testimonios de terceros, refiriere que: "de los Charcas al Chile pasó Almagro mucho trabajo, hambre y frío [...] Heláronse muchos hombres y caballos, pasando unas grandes sierras nevadas, donde también perdió su fardaje" (1901 [1552]: 291). Agustín de Zárate afirma:

Grandes trabajos pasó Don Diego de Almagro y su gente en la jornada de Chile [... y y sobre todo, les hizo gran daño el demasiado frío que pasaron en el camino, así del aire tan helado, como después al pasar de unas sierras nevadas, donde acaesció a un capitán que iba tras Don Diego de Almagro [...] quedársele muchas personas y caballos helados [...] que cuando volvió [...] halló en muchas partes algunos de los que murieron a la ida [...] con los caballos de rienda también helados, y tan frescos y sin corrupción como si entonces acabaran de morir; y así, fue gran parte de la sustentación de la gente que venía los caballos que topaban helados en el camino y los comían (Zárate 1901 [1555]: 256).

A su vez, Pedro Cieza de León afirma "De esta tierra fue descubriendo Almagro hasta llegar a Chicuana [sic], (1909 [1553]: cap. XCIV):

[...] Partido Almagro de aquella tierra [...] Subiendo por una quebrada [...]; toparon un aposento pequeño donde se alojó Almagro, vieron no muy lejos grandes sierras blancas de la mucha nieve que tenían: [...] Salió la guía con algunos españoles delante, como dieron con la nieve, era tanta que ni se parecía camino ni roca ni otra cosa que su blancura, cayendo a la continua copos de ella. [...] Pues, como partió el adelantado anduvo aquel día muy gran trabajo hasta llegar a unos tambillos, donde durmió, sintiendo bien el frío que hacía; y creo me dijeron holgó allí un día [...], prosiguió su camino. El austro ventaba tan recio que ni sentían narices 


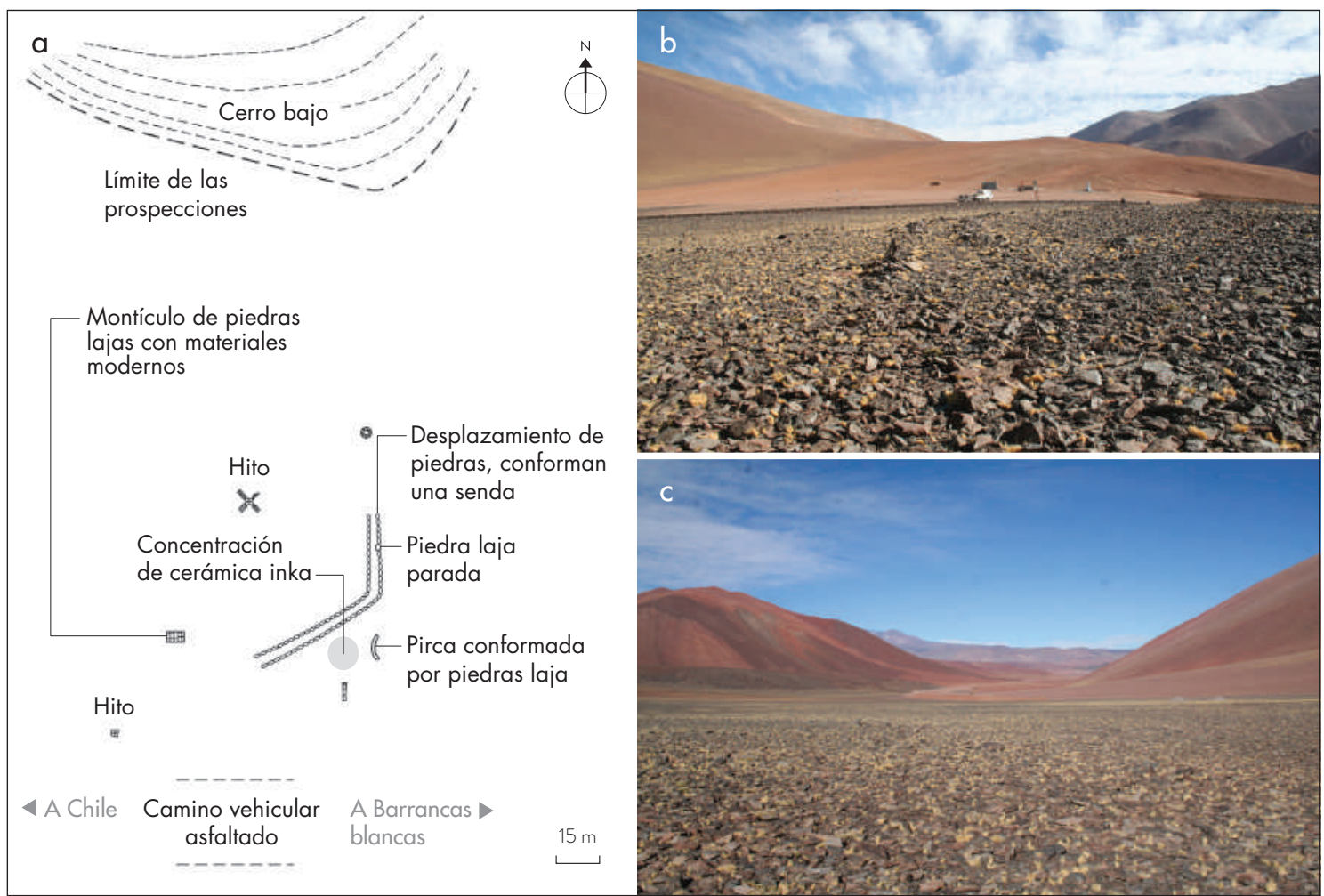

Figura 10: a) croquis con las estructuras pircadas del sitio inca del paso de Pircas Negras; b) vista general del paso de Pircas Negras; c) vista del sector de aproximación al paso por el lado argentino (“"llanada” de la crónica?). Figure 10: aa) sketch of the dry-stone structures at the Inca site of Paso de Pircas Negras; $\boldsymbol{b}$ ) general view of Paso de Pircas Negras; $\boldsymbol{c}$ ) view of the approach to the pass on the Argentine side ("llanada" de la crónica?).

ni orejas, [...], quemábanseles la nieve, de la cual caía tanta que era cosa de espanto. De lo alto del puerto del valle de Copayapo había doce leguas, como otro día anduviesen llegó a dormir ribera de un río en otro tambillo al pie de un alpe, otro día, [...], anduvieron hasta que salieron de aquel tormento $[\ldots]$, los que atrás quedaron, $[. .$.$] como entraron en$ las nieves mayor fue la fatiga, [...]; comenzaron a se quedar muchos de los indios e indias y algunos negros y españoles muertos. Comían algunos con hambre unos limos, que se crían entre lagunas, leña para hacer lumbre no había otra que estiércol de ovejas y unas raíces que sacaban debajo de tierra $^{11}$. [...] Muriéronse treinta caballos, y muchos indios e indias y negros $[\ldots]$ muchos de los indios vivos comían a los muertos: los caballos, que de helados habían quedado, de buena gana los comían los españoles, mas si paraban a los desollar se vieran como ellos; [...]; cuando venía la noche, lo mejor que podían armaban sus tiendas entre tanta nieve como sobre ellos caía" (1909 [1553]: Cap. XCIV).

En cuanto a las huestes que venían más atrás al mando de Rodrigo Orgóñez, expresa:

fueron a Chicuana [sic], [...] Tenían noticias de los Alpes de Chicuana [sic], caminaron hasta llegar a un río, que llaman río Bermejo [...] Dende algunos días llegaron a vista de las grandes sierras nevadas, [...]; como mejor pudieron entraron en las nieves, [...] Fue tan grande el frío que se murieron los más de los negros, y indios e indias; y los que se escaparon fueron con los dedos comidos o ciegos de los ojos. [...], siendo pasados cuatro días, se hallaron fuera de las nieves, dejando muertos los dos españoles y muchos indios e indias y negros, y veinte y seis caballos con sus sillas y aderezos, muchas petacas y líos de ropa (1909 [1553]: cap. XCVI).

Finalmente, quienes venían aún más rezagados al mando de Juan de Rada, "supieron cómo había los puertos nevados y cómo Ordóñez estaba en Copayapo. Topaban algunos negros e indios de los que habían quedado cansados, veían estar muchos muertos que era lástima de los ver" (1909 [1553]: Cap. XCVII).

Gonzalo Fernández de Oviedo y Valdés, cuyo hijo murió ahogado en la expedición de Almagro, nos dice:

fue muy conviniente invernar allí [...] porque habiendo, como hay, desde aquella provincia [la de Chicoana] á la de Pocayapo cincuenta jornadas de despoblado, excepto tres o 
cuatro poblezuelos de caribes [...] Pues como el camino fué tan largo é los trabajos extremados y la falta de bastimento, llegó este ejército al pié del puerto con los caballos muy fatigados é los españoles muy desfigurados y cansados, é como en el puerto había siete jornadas [...] como por el frío é demasiados vientos [...], adelantóse el capitán general con veinte de a caballo, [...], en tres días [...], entró en la dicha provincia [...] Porque es no tan solamente espantosa cosa pasar aquel puerto, mas aún acordarse dello los que lo vieron tornaba a renovar su temor [...] En fin, el mejor librado perdió su hacienda é quedó sin servicio de indios é negros, que se les murieron, [...] , y los que mejor les fué, perdieron sus caballos y ropas" (1901 [1557]: 223, 225, 226).

Pedro Mariño de Lobera expresó en su momento que: "Poco después [...] llegó allí el Adelantado con el ejército, y [...], fueron todos [...] hasta otra provincia llamada Chihuana $[\mathrm{sic}] .[\ldots]$, y prosiguió su camino a otra provincia llamada Quirequire. En esta descansó algunos días, [...] fue prosiguiendo por sus jornadas hasta dar en una campaña desierta, aunque en medio de ella estaba un fuerte de dos tapias de alto" (Mariño de Lobera 2003 [1575-1576]: Libro Primero, cap. II), avanzando después hasta: "llegar al río [falta] que es muy famoso en los confines del reino de Tucumán”, arribando más adelante: $[\ldots]$ a las faldas de una sierra, donde en cierto lugar $[\ldots]$ una carta colgada [...]" que el Adelantado hace leer a $[\ldots]$ todo el campo para animarlos con la esperanza a proseguir su viaje y a sufrir con ánimo los trabajos de un despoblado, que, según la carta les decía [...], es el mayor que se sabe, porque tiene de travesía más de ciento y veinte leguas, donde los tres soldados se vieron en gran aflicción de sed y hambre" (Mariño de Lobera 2003 [1575-1576]: Libro Primero, cap. III).

\begin{abstract}
Fueron tales estímulos para los españoles las nuevas [de la carta] [...] que [...] se fueron entrando por lagrande y fragosa cordillera [...], donde al pasar un portezuelo [...] descubrieron una llanada de dos leguas, por la cual corre ordinariamente un viento tan furioso, helado y penetrante, que pone a los pasajeros en riesgo de vida [...] se partió luego el Adelantado con cincuenta hombres de a caballo [...], fue tanta la diligencia con que el Adelantado y el escuadrón fueron caminando, que a pocas (falta) por el gran valle de Copiapó [...] de algunas horas llegó el ejército (falta) el mismo día no menos fatigado del rigor del camino, que lleno de compasión, por haberse muerto al pasar el páramo cinco mil indios hombres y mujeres, de los que iban del Perú en su compañía y servicio, y también algunos negros esclavos de los españoles, y más de treinta españoles [...]" (Mariño de Lobera 2003 [1575-1576]: Libro Primero, cap. IV).
\end{abstract}

Antonio de Herrera, autor de las denominadas Décadas y que no vino a América, se basa en las publicaciones de cronistas y el contraste de las mismas con documentación de la época, logrando una obra amplia y bien considerada por la crítica. Sobre la cuestión que nos ocupa refiere que:

Don Diego de Almagro, [...] se adelantó con una buena tropa de caballos para pasar con diligencia los puertos [...]; llegado á los puertos, no se descubría sino altísima nieve y nevaba terriblemente: comenzólos a pasar, [...] hasta llegar á unas casillas, adonde con gran frío pasaron la noche, [...] $\mathrm{y}$ tras estos trabajos, hallaron que desde lo alto del puerto había doce leguas al valle de Copayapo; pero esforzándose lo que podían, otro día llegaron al valle (en total fueron tres días para el cruce) [...] el ejército (los que venían detrás) en entrando por las nieves fue muy general la angustia; [... y si se paraban se quedaban helados, [...] era mayor la congoja de la noche, pues no había ningún abrigo; en fin, murieron treinta caballos y muchos indios y negros arrimados á las rocas se les salía el alma, y la hambre llegó a tal extremo que los indios vivos comían á los muertos; y los castellanos de buena gana comieran los caballos helados [...] (Herrera 1901 [1601-1615: 477).

Antonio de Herrera agrega que las huestes que más tarde siguieron los pasos de Almagro por el mismo camino, esta vez con Rodrigo Orgóñez a la cabeza, luego de detenerse en Chacuana [sic] y saliendo de la misma:

llegaron a un río, el cual llamaron río Bermejo, [...] y desde algunos días descubrieron las sierras nevadas, que les causaron espanto, temiendo el frío; [...] animosamente entraron en ellas, [...] que aunque armaron los toldos, se murieron los más de los negros y los indios, y los que escaparon salieron ciegos ó con los dedos comidos. [...] y cayó tanta nieve que aquel lugar fue su sepultura con sus negros é indios y caballos. [...] y tomando ánimo como mejor pudieron en cuatro días salieron de aquel grandísimo peligro, dejando muertos los dos referidos castellanos, muchos negros é indios y veinte y seis caballos con sus sillas y aderezos [...]; quedáronse muchas petacas de ropa, y casi todo el bagaje [...] (Herrera 1901 [1601-1615: 480).

Si bien, no agotamos con estas fuentes de cronistas todas las versiones existentes sobre el paso de Almagro y tampoco nos adentramos en el análisis crítico sobre las afirmaciones de esa producción, nos parece que referirnos a las de Bartolomé de Segovia o Cristóbal de Molina despierta la confianza de protagonistas de la expedición y con esto nos acercamos mejor a lo que efectivamente pudo ocurrir. En este tipo de datos, más allá de los que pueden ocurrir por apreciación, no habría errores intencionales movidos por determinados intereses, máxime en una obra que se orienta a la crítica del modo en que se realiza la conquista. 
En esta crónica se dice que desde Chicoana a Copiapó hay casi 150 leguas. Según las diferentes estimaciones y su transposición al sistema métrico podrían equivaler a unos $861 \mathrm{~km}$, tomando la media para la legua del siglo XVI entre 5572 y $5914 \mathrm{~m}$; o bien de unos $1050 \mathrm{~km}$ si consideramos la media aproximada de la relación legua/ $\mathrm{km}$ de autores como Pollard -según nos parece unos 6,7 $\mathrm{km}$ por legua-, en Vitry 2007). Si bien, como distancia tiene el valor relativo o estimativo de un observador como el clérigo autor del escrito, pudo significar a la vez una distancia con la que se manejaban en la expedición, quizás sobre bases de estimación más ajustadas.

A su vez, en Molina está la mención de 13 jornadas de despoblado y puerto para lograr el paso andino, mientras que de este último a Copiapó se indica el trajinar por 5 jornadas.

Otros cronistas coinciden a grandes rasgos con estas estimaciones, refiriéndose a leguas y jornadas. Cieza, por ejemplo, con sus 12 leguas desde lo alto del puerto que utilizan hasta alcanzar Copiapó, pasaje que tardan cuatro días en realizar. Fernández de Oviedo da 50 jornadas despobladas de Chicoana a Copayapo y 7 jornadas en el puerto, aunque Almagro pasaría en 3. Mariño de Lobera afirma que la travesía era de 120 leguas -si es que se refería a la que nos ocupa-. Herrera (1901 [1601-1615]) explica que de la altura del paso había 12 leguas a Copiapó y que fueron 3 jornadas las del cruce de Almagro y 4 las de quienes le siguieron más tarde.

Sin entrar, como dijimos, al análisis y crítica histórica de las fuentes, está claro que, sea por el acceso a los escritos de otros o sea por la coincidencia de testigos $\mathrm{y}$ otros testimonios, se aprecia un marco general de similitudes con lo expuesto por Molina con respecto a distancias y jornadas. ${ }^{12}$

Sobre esta base, las 50 jornadas de Fernández de Oviedo podríamos referirlas a las 120 a 150 leguas de distancia entre Chicoana y Copayapo que proponen los otros autores, con lo que nos daría una estimación grosera de avance de 3 a 4 leguas diarias (unos 17 a 23 $\mathrm{km}$, o bien unos 20 a $27 \mathrm{~km}$ ). Esta distancia es una posibilidad del trajinar de las huestes y campo de Almagro y guarda cierta verosimilitud, como la de las 5 jornadas o las 12 leguas que distan del puerto que pudieron haber tomado para alcanzar a Copiapó según Molina. Con esto alcanzaríamos una distancia desde el paso de los Andes a Copiapó de unas 12 a 15 leguas (aproximadamente 69 a $86 \mathrm{~km}$, o bien unos 80 a $100 \mathrm{~km}) .^{13}$
Más allá de las imprecisiones de los dichos y de cualquier cálculo que hagamos sobre estas bases, pueden estimarse guarismos de distancias recorridas y jornadas para realizarlas que apuntan más al pasaje por los pasos riojanos al oeste de Laguna Brava que por los pasos de Catamarca, en especial el denominado San Francisco.

En este sentido, la enunciación de la distancia total al puerto o paso que finalmente los llevaría al Copayapo de entonces, con los despoblados que anuncian pasar, hace más verosímil alcanzar la ciudad por el oeste riojano, tal como se hace hasta hoy por los varios pasos que hay camino a Copiapó, más que por el paso de San Francisco, más alto y más distante de esta localidad. Incluso, la distancia que marcan los cronistas del puerto a Copiapó, entre cinco y siete jornadas o bien unas 12 leguas, se condice más con los pasos riojanos a que nos referimos que con el catamarqueño de San Francisco. ${ }^{14}$

Ahora bien, que el paso elegido por la expedición de Almagro haya sido el de Comecaballos nos parece una cuestión no resuelta. Por un lado, no hay evidencia arqueológica que lo confirme y por otro lado, las fuentes describen el puerto utilizado como una zona llana, batida por los vientos -habitual en cada paso de esas alturas-, lo que implica unas dos leguas de extensión. Este no es el caso de Comecaballos o de los otros pasos cercanos que pueden llevar a Copiapó (La Ollita y Peña Negra por ejemplo), pues, después de la característica subida empinada "caen" en un corto trecho a quebradas del lado chileno, con la única excepción del paso de Pircas Negras, que pareciera reunir las condiciones de "llanada" extensa, tal como propone Mariño de Lobera (2003 [1575-1576) -y podría colegirse que lo mismo hace Molina-. Este paso reúne hasta hoy en su superficie vestigios de instalaciones inca de cierta amplitud en su superficie, considerando que se hallan en un sitio de tránsito, aunque se encuentran muy deterioradas. ${ }^{15}$

Por otra parte, las alturas de los pasos riojanos son menores a la del paso de San Francisco que tiene poco más de $4700 \mathrm{msnm}$, contra unos $4500 \mathrm{msnm}$ de los primeros (con excepción de La Ollita)-.

Por lo tanto, tal como proponen los autores en general (seguir en Raffino (1995) y en Vitry (2007) las menciones de los mismos y de sus propuestas), estimamos que el pasaje de Almagro hacia Copiapó se hizo a través de los Andes por La Rioja. No obstante, no creemos que fuera por el paso de Comecaballos, dejando al mismo y a pasos vecinos como posibilidad de ese tránsito, hasta que encontremos vestigios suficientes para contrastar 
la hipótesis con respecto a algún paso en particular o a pasos próximos entre sí. La envergadura de la expedición, según se indica en las crónicas, pudo hacer necesario desplazarse por varios pasos o puertos o, tal como se los denomina en la jerga geológica y topográfica, por sus "desechos". ${ }^{6}$

Vitry (2007) retomó recientemente el tema del derrotero de Almagro en el NOA contrastando positivamente muchas de las localidades en el avance de Almagro en 1536 por el actual NOA. Lo hizo con ayuda del conocimiento del terreno, el trabajo con los escritos de los autores modernos y el itinerario indicado por Juan de Matienzo. El trabajo fue realizado principalmente en las provincias de Salta y de Catamarca. Al acercarse a la provincia de La Rioja y a la posibilidad del paso de los Andes por el oeste de la misma, la propuesta del autor debió soportar la imprecisión respecto a la geografía del área y la infraestructura inca, producto de su menor conocimiento y el de los otros autores citados.

Justamente, una tarea pendiente consiste en complememtar lo que sabemos sobre el o los Caminos Incas utilizados en el avance hispánico, facilitados seguramente en su transitar por la ayuda de Paullu y sus colaboradores, con el uso que pudo hacerse del resto de la infraestructura, coasociada al mismo, por ejemplo los tambos, así como la escala de esas construcciones en relación con la envergadura de las huestes, personal de servicio, yanaconas, indígenas y negros, así como de los elementos del campo de Almagro.

Más allá de las reiteradas menciones de "despoblados" o de poblados menores en las crónicas, a partir de Chicoana, Chicuana, Chihuana o Chacuana, como es citada en esos escritos y donde quiera que estuviese localizada en Salta, o incluso de la también mencionada por Mariño de Lobera -y por otros-, Quirequire -o Quire Quire- (2003 [1575-1576]: libro primero, cap. II: 4), puede deducirse que, al menos aquella si efectivamente son dos distintas, debió reunir escala suficiente en sus recursos e infraestructura como para ser nombrada por todos y soportar las tres principales oleadas de los conquistadores, como las mismas fuentes lo señalan. Quedan para más al sur la relación que apunta a escalas menores, aunque allí se halle el imponente El Shincal de Quimivil, utilizado probablemente en el avance, de la posterior localidad de Londres en Catamarca, con más de $70.000 \mathrm{~m}^{2}$ de superficie ocupada por recintos (Raffino 2004: 29), área pasible de haber estado bajo cubierta. ${ }^{17}$
Luego, se halla la conspicua fortaleza de indígenas locales o regionales, según las interpretaciones de las fuentes, que debe tomarse por la fuerza (Mariño de Lobera 2003 [1575-1576]: libro primero, cap. II: 4-5) y que autores como Raffino (1995) han identificado con la Watungasta catamarqueña. Con ésta se propone el punto de inflexión hacia el oeste y a los posibles puertos del paso -Raffino 1995: 40; 2004: 40-, no indicándose en las fuentes otras locaciones de cierta envergadura, más allá de la referida "Talombones" (Matienzo en Berberián 1987: 207) y de la interpretación que identifica El Shincal con la mención de Matienzo sobre Londres (Matienzo 1987 [1556]), la que sería otro punto en la progresión de Almagro hacia Copiapó.

Las fuentes no mencionan funcionarios incas preexistentes al paso de Almagro por el NOA. Síl lo hacen con respecto al norte chico y área central chilena. Surge entonces la pregunta sobre cómo contrastar la existencia en ese momento, o en el pasado inmediato, de tal estatus en el noroeste de nuestro país, dadas las menciones hechas sobre el país vecino, las que deberían tener su correlato en el nuestro. En todo caso estas referencias parecen constreñidas, en relación a este primer ingreso hispano y según las crónicas que consultamos, a los dichos de Mariño de Lobera (2003 [1575-1576] $)^{18}$ y de Fernández de Oviedo ${ }^{19}$ (1901 [1557]). ${ }^{20}$

Con este panorama, los establecimientos incas que siguen hacia el oeste son de menor escala, con la excepción del correspondiente a Laguna Brava de entidad media ${ }^{21}$, hasta alcanzar las quebradas y pasos propiamente hacia Copiapó, con estructuras menores, claramente incas en su patrón arquitectónico o modificadas por esta arquitectura, aprovechando bases indígenas locales/regionales de instalación estacional previa (fig. 11).

Los últimos kilómetros hacia el oeste en dirección a los pasos ofrecen un paisaje de altura que se caracteriza por los "despoblados" descritos por los cronistas, donde la presencia humana y bastimentos a disposición serían a una escala muy menor. Se halla arquitectura pircada de pocos metros de superficie que pudiera estar bajo cobertura, siendo excepcionalmente apta para albergar personas, animales y bastimentos de la envergadura de la expedición de Almagro, aun cuando avanzara por contingentes separados en espacio y tiempo. Quizás el único aspecto que no coincide con las referencias de los cronistas es la ausencia de mención acerca de la proliferación de vicuñas, aunque se hable de las deyecciones de las "ovejas" como posibilidad de lumbre. ${ }^{22}$ 

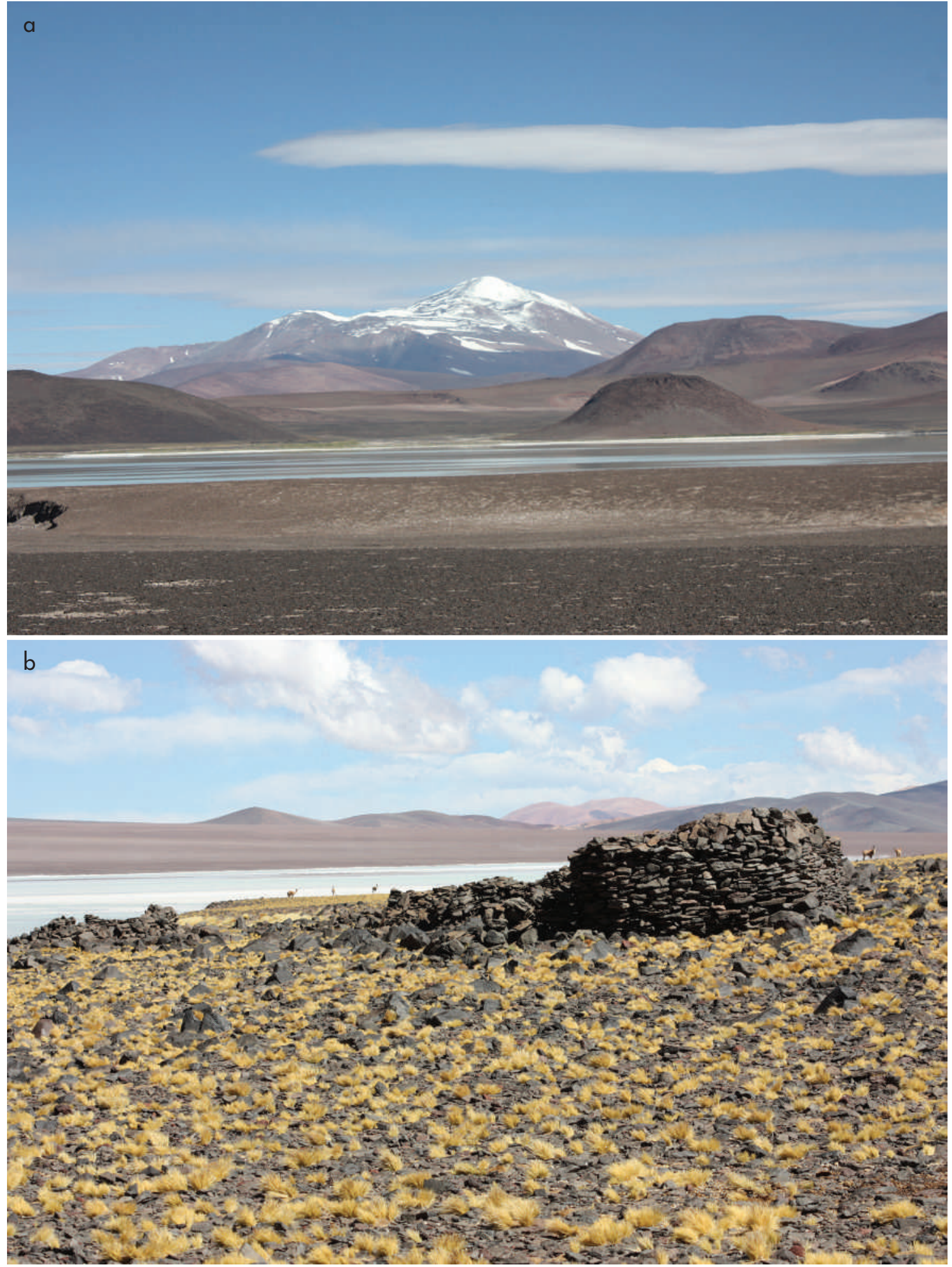

Figura 11: a) vista general de Laguna Brava; b) imagen con un sector del tambo de Laguna Brava. Figure 11: a) general view of Laguna Brava; $\boldsymbol{b})$ photo of part of the Laguna Brava tambo. 
Con alta probabilidad, una de las razones de la profusa presencia de parapetos de caza, poblados de esta índole y de instalaciones inca sobre los mismos o de impronta propia, fuera el manejo de estos animales por su estimado pelo para textiles y otras posibilidades económicas. ${ }^{23}$

Nuestras prospecciones en el área de Laguna Brava y hacia el oeste, así como las que realizamos en el área del Parque Nacional San Guillermo en San Juan, colindante por el sur, demuestran la proliferación de estructuras de época inca y anterior. Respecto de la organización estatal, esto implica claramente un patrón de instalaciones que bordean lagunas y salinas, flanquean quebradas con cursos de agua más o menos activos y se ubican, asimismo, en la desembocadura de las mismos en los colectores regionales. Esto sin contar las instalaciones relacionadas con el culto, por ejemplo aquellas ubicadas en los cerros, entre otras. ${ }^{24}$

Para la cuestión que nos ocupa, solo señalamos algunas instalaciones claramente inca, de escala o rango medio para el área. Entre ellas, la denominada Laguna Brava, en el extremo noreste de la Laguna, la de Confluencia, ubicada en la desembocadura del arroyo o río de la Peña Negra en el Río Blanco, con una matriz arquitectónica intermedia entre lo local y lo introducido. Aquí hallamos alfarería colonial de los tiempos de Almagro. Cerca de esta instalación existe un tambo de regular envergadura, ubicado en la quebrada del arroyo o río de Las Pailas, en el sector limítrofe con la provincia de San Juan, curso que desemboca en el Blanco.

\section{CONCLUSIONES}

Nuestro interés sobre investigaciones científicas de arqueología e historia regionales atinentes a los desarrollos de las poblaciones locales y la incidencia inca, permitió avanzar sustancialmente en el conocimiento de las instalaciones preexistentes y las de la organización estatal, en una amplia franja territorial. En el caso riojano, dicha extensión va desde la Laguna Brava a la cordillera de los Andes, entre el límite con el Parque Nacional San Guillermo del noroeste de San Juan por el sur y la latitud del cerro Pissis por el norte, en el límite de la Rioja con Catamarca.

En la actualidad, hemos reconocido numerosos sitios arqueológicos del sector, su relevamiento, planimetría y prospección intensiva. Contamos con los resultados de la excavación de varios de ellos, el estudio de los materiales y la adscripción cronológica, tanto la relativa a la caracterización tecnológica y de los tipos de artefactos (como los cerámicos) como la derivada de los análisis por C14 y TL, entre otros.

Hay profusión de hallazgos de época inca, varios de ellos de envergadura en términos de escala relativa para establecimientos de altura, como la presencia de sitios de épocas anteriores y posteriores a la dominación inca. Los sitios están representados por la reutilización de las locaciones o la instalación de otras nuevas para uso de arrieros y viajeros desde la época colonial hispana, con fuerte incidencia del tránsito de arreos de vacunos y equinos en época republicana, sobre todo a partir de la segunda mitad del siglo xIX y primer tercio del xx.

En este contexto, no pueden faltar las referencias a fuentes bibliográficas y los contrastes documentales con el registro arqueológico, tanto de archivos como de aportes derivados del trabajo crítico sobre escritos de cronistas, clérigos y soldados de los primeros tiempos de la dominación hispana, entre otros.

A partir de la doble vertiente metodológica de la arqueología y la historia concentramos finalmente nuestro interés en lo atinente a la expedición de Diego de Almagro y su tránsito por los pasos cordilleranos de los Andes en el Noroeste Argentino en 1536, con destino trasandino inicial en el Copayapo de entonces. Estimamos que nuestra contribución avanza los estudios al respecto.

Dejamos para otra ocasión la labor de profundización y conclusiones de nuestros estudios sobre dominio inca y poblaciones locales en el sector analizado, concentrándonos en aquellos que atañen al primer paso hispánico a través de los Andes del Noroeste Argentino. No obstante, queda claro que esos estudios facilitaron el que nos ocupa ahora pues, por primera vez, proceden al registro arqueológico del conjunto de quebradas y pasos que facilitan el acceso trasandino en la porción del actual territorio argentino que abordamos. Este conocimiento implica un claro avance y, en particular, contribuye a las hipótesis que puedan plantearse sobre el tránsito de Almagro. Podemos ahora contrastar este derrotero posible con la comprensión propia de la experiencia en terreno, situación que no detentan quienes nos precedieron con sus propuestas acerca de los pasos que pudo utilizar Almagro y compañía.

Desestimado el derrotero por el paso de San Francisco en Catamarca, acentuamos esta premisa con el apoyo de la la descripción del licenciado Matienzo, la fuente sobre vialidad inca más pormenorizada de 
la época colonial hispana inicial. La enumeración de tambos y su relación con el Camino Inca que los une, le llevó a sumar a su enumeración de instalaciones hasta los "Talombones" y cercanías, la mención de que hacia el oeste está la cordillera "de Almagro" y, sobre todo, la orientación de la vialidad, en esa progresión occidental, hacia la Londres de entonces, El Shincal inca. Todo ello basado en el conocimiento de los caminos de entonces por el Noroeste Argentino y de la experiencia por los mismos de Diego de Almagro y Diego de Rojas. Dicha información no hace plausible que Almagro y su campo virara de este notable establecimiento inca - un "nuevo Cuzco" - hacia el pasaje de San Francisco al noroeste, reforzando nuestra hipótesis del paso por el occidente andino riojano, en la latitud del Copayapo indígena.

Dicho esto, la progresión nos lleva al área de Laguna Brava y al occidente de la misma, enfrentándonos con los pasos andinos de la actual cordillera en el límite internacional, ubicados a lo largo de unos $30 \mathrm{~km}$ en línea recta, distancia que media entre los pasos de Pircas Negras en el norte y La Ollita en el sur. El Adelantado, sus acompañantes y pertrechos con alta probabilidad pasaron por esta fracción.

Todos los pasos fueron reconocidos por nosotros, denotando sus instalaciones de altura y de los trayectos por las quebradas de acceso a los mismos. Los itinerarios fueron posibles siguiendo en sentido inverso el curso de arroyos y ríos de distinta envergadura, generalmente de nombre homónimo con el paso, que fluyen a colectores como los ríos Salado y Blanco, o como en el caso del propio arroyo Peña Negra, afluente del Blanco.

Son paisajes puneños y altoandinos con lagunas, salinas y mayor o menor profusión y extensión de vegas, lo que constituye un sustrato relevante en la sustentación de flora y fauna característica y base importante para la logística necesaria del tránsito a los pasos. El ganado montado y arreo dependen de esas condiciones para sobrevivir en un área con condiciones extremas, particularmente si se trata de soportar cargas de envergadura en lapsos muy acotados, como las propias de centenares a miles de personas en tránsito, con sus bagajes y ganados, entre otros.

Por lo tanto, no es de dudar que el paso de Almagro fuera difícil y que, en buena medida, soportara vicisitudes del tenor de las que los cronistas describen, más allá de la exactitud que las descripciones pudieran conllevar en relación con los hechos o de las semblanzas heroicas que la literatura de la época acostumbrara narrar.
En lo fáctico no huelga la presencia de Paullu, pues al prestigio de la panaca gobernante inca sumaría el saber, propio o por asesores, sobre poblaciones y territorios, sobre su organización e infraestructura. Por ello, éste podría indicar con bastante precisión, incluso para la nueva logística que afrontaba desde su conocimiento vernáculo, itinerarios, albergues, despensas y pasos más aptos para la realidad de la organización de campo de Almagro.

Con estas bases repasamos las crónicas, cuyo análisis nos permite atender verosímilmente expresiones como las de la extensa "llanada", que se ajusta más al paso de Pircas Negras o las que interpretamos refieren al tránsito por más de un paso, lo que es posible habida cuenta de la existencia de los "desechos" de los mismos, la cercanía entre ellos y la posibilidad de unirlos pasando de una quebrada a otra en cercanías de sus nacientes.

Si bien, la expresión moderna Comecaballos es sugerente para un paso, una quebrada y un arroyo en relación con el contexto del relato de las crónica, y que su tránsito hasta ponernos en la "bajada" trasandina implique una veintena de kilómetros desde la desembocadura en el río Salado, razón por la cual no resulta excesivamente penoso, esto no es suficiente para contrastar positivamente la hipótesis que lo sustenta como principal en el itinerario de Almagro. Hasta donde sabemos no hay precisión sobre la época y origen del nombre. Podría argumentarse que otros pasos tienen una denominación que aludiría a la expedición, por ejemplo "Peñasco de Diego", ubicado en las cercanías del paso de Pircas Negras. ${ }^{25}$

Por otra parte, si nos atenemos a la infraestructura inca preexistente en el camino y en las instalaciones asociadas, las que debieron jugar el papel logístico que presumimos, Comecaballos cuenta en rigor y según nuestro registro solo con la elemental y no de envergadura. Estas se desarrollaron en base a instalaciones anteriores, sin que el propio paso cuente con evidencias de arquitectura. En efecto, no presentan hasta hoy los montículos que hemos reconocido materiales que aludan a ese momento. Con las excavaciones arqueológicas solo pudimos determinar evidencia antropológica en uno, referida a huesos humanos, que datamos hacia la vir/Ix centuria de la Era, con lo que se denota el uso del paso por indígenas y no da cuenta del episodio colonial del siglo XVI.

Si bien no podemos descartar la hipótesis del tránsito de Almagro por el paso de Comecaballos, tam- 


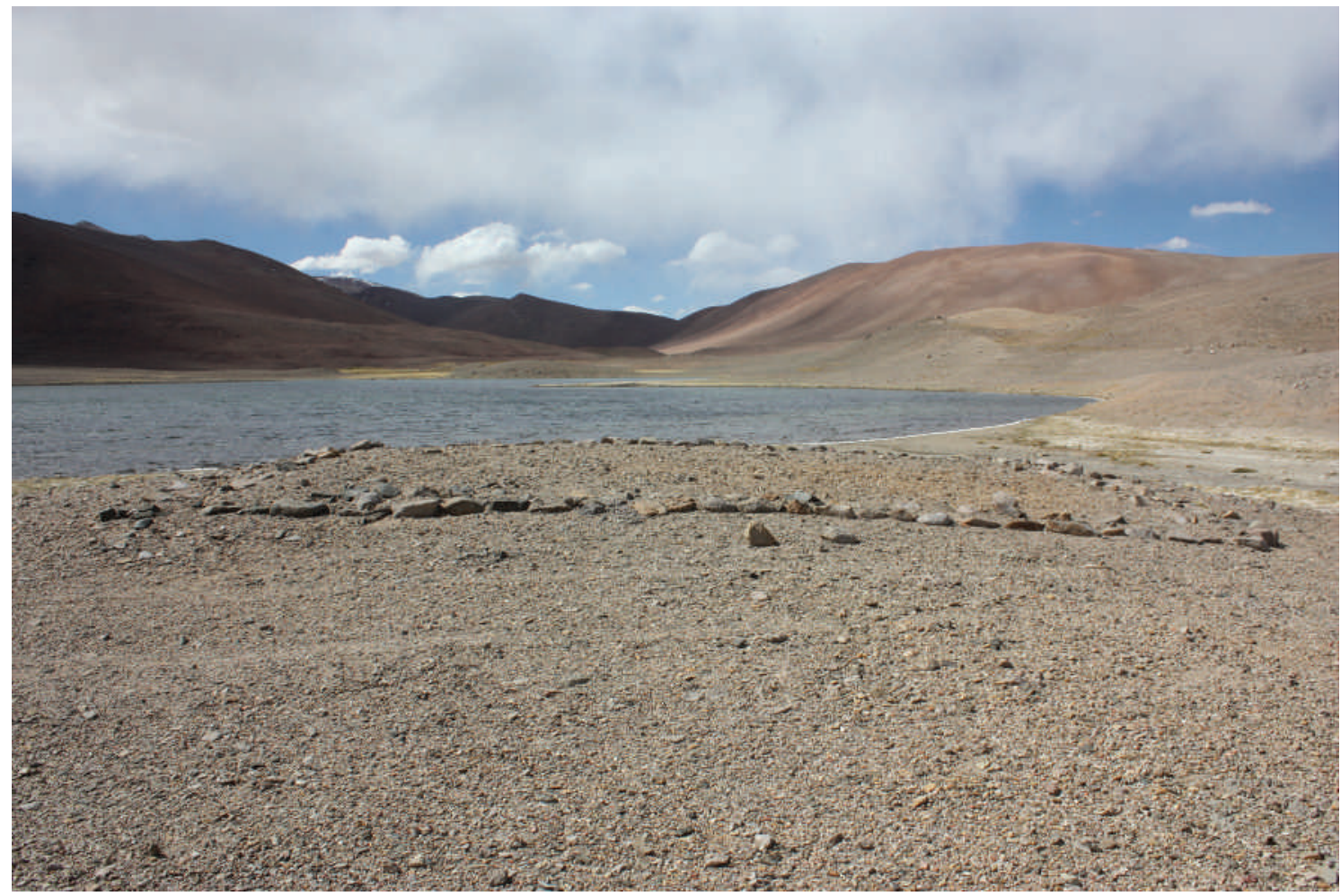

Figura 12. Estructura pircada, con toda probabilidad de época incaica y de índole ceremonial, sita en la margen sur de una laguna del sector del paso de La Ollita. Figure 12. Dry-stone structure, most likely from the Inca Period and used for ceremonial purposes, at a site on the shore of a lake in the area of Paso de la Ollita.

poco podemos sustentarla con evidencia arqueológica, quedando para nosotros como una posibilidad más en las conjeturas, más aun cuando carece de suficiente contraste con la evidencia que pudiera aportar el registro de la banda occidental de los Andes.

Justamente, el registro de la evidencia inca por ambas bandas cordilleranas muestra el mayor énfasis de instalaciones de esta época y anteriores, aún de relictos de vialidad, a partir del nodo que conforma el tambo de Confluencia, en la zona de unión del arroyo de Peña Negra con el río Blanco, lugar del tránsito hacia el cordón limítrofe del cerro El Potro y, más relevante en el contexto que nos ocupa, del inicio, desde el cercano Río Salado, del itinerario por la quebrada de Peña Negra, con la posibilidad de alcanzar el paso homónimo, su desecho y el paso de La Ollita, que están en el origen del camino trasandino más directo a Iglesia Colorada/ Choliguín y Copayapo.

De acuerdo a nuestro registro de los establecimientos del área, solo en el Ttambo de Confluencia reconocimos cerámica de manufactura según canon europeo, la que se remontaría al siglo XVI según datación TL. En los grabados de una roca de la margen derecha del arroyo Peña Negra reconocemos cruces que estimamos serían más propias de la época colonial que de la acción de arrieros del siglo XIX o posteriores.

Por lo tanto, sostenemos la hipótesis de que el avance almagrista se habría realizado por los pasos de La Ollita/Peña Negra, aunque no desconocemos las otras alternativas de Comecaballos, Pircas Negras y sus correspondientes desechos. Sustentan esta hipótesis, entre las más importantes consideraciones: la sucesión de vegas y de establecimientos relacionados con las mismas, de envergadura relativa a su escala altoandina, pero que destaca en el concierto de los pasos tratados aquí; la existencia de infraestructura al pie o en los mismos pasos por ambas bandas cordilleranas; y el reconocimiento de la antigua vía empedrada en la vertiente occidental de La Ollita, la vía más directa a Copiapó a través de los Andes.

Seguiremos trabajando sobre estas alternativas procurando la evidencia arqueológica que pudiere 
despejar las incógnitas y resolver un problema que, si bien es de importancia relativa, adquiere mayor significación en cuanto al decurso de nuestras investigaciones sobre lo inca y las poblaciones locales de los Desarrollos Regionales. Este es uno de los casos en que con mayor fuerza puede decirse que, si utilizamos el aforismo de que una dominación pavimentó el camino de la siguiente, la impronta inca que bien manejarían Paullu y su grupo sirvió de base para el desplazamiento del primer ingreso hispánico mancomunado al Noroeste Argentino. No dudamos que este movimiento alcanzó la actual provincia argentina de La Rioja y sus pasos cordilleranos de los Andes.

RECONOCIMIENTOS A las instituciones a las que pertenecemos (CONICET, UNCUYO, UNLAR) y las que sostuvieron estos trabajos (ANPCYT y CONICET). Agradecer puede conllevar la ingratitud de las limitaciones de recordar, por lo que tratamos de evitarla con una referencia general de reconocimiento a los miembros de nuestro equipo de investigaciones, como asimismo nos es también grato referirnos a la predisposición positiva y los apoyos institucionales necesarios de las autoridades nacionales y provinciales que permitieron las labores, al igual que las múltiples ayudas que recibimos de la comunidad de sectores próximos a las áreas de estudio. Reconocemos igualmente la labor de los editores y de los evaluadores de nuestra contribución.

\section{NOTAS}

${ }^{1}$ Denominación de las alternativas de pasos cordilleranos conexos a uno principal que tiene nombre propio.

${ }^{2}$ En la actualidad, algunas estimaciones arrojan la cifra de 16 animales por $\mathrm{km}^{2}$ para San Guillermo y probablemente menos de la mitad para Laguna Brava. A diferencia de las dificultades logísticas que afrontábamos hace años para acceder al paso de Comecaballos, la acción gubernamental estatal de la Provincia de La Rioja llevó en el último tiempo a abrir y mantener anualmente, por esa conmemoración, una huella para tránsito de vehículos. A través de ella se alcanza con cierta facilidad el límite con Chile.

${ }^{2}$ Hans Niemeyer (1986: 201-202), quien registra una intensa actividad de prospección arqueológica en la cuenca alta del Copiapó, tampoco menciona haber accedido al paso de Comecaballos.

${ }^{3}$ Como se aprecia, la tabla 1 refiere resultados TL sobre tiestos hallados en los diferentes sitios estudiados. Estos pueden no concordar con la cronología absoluta de los intervalos establecidos para sus tipologías. Como hemos referido en otras contribuciones (v.g.: Bárcena 1998) los resultados TL tienen, a nuestro juicio, la ventaja de ordenar relativamente la sucesión de las cocciones cerámicas de los tipos, con la desventaja de que en ocasiones sus guarismos cronológicos absolutos pueden no corresponderse con resultados que los ubiquen en el período esperado.

${ }^{4}$ El resultado proporcionado por LATYR fue "Moderno" que significa por convención (Stuiver \& Polach 1977) cualquier edad comprendida entre 0 y 200 años radiocarbónicos.

${ }^{5}$ La cruz puede tomarse, si fuera de la época en que ubicamos hipotéticamente esa parte de los grabados, como un ícono hispánico de protección en los espacios de tránsito -máxime con las características de los que estamos refiriendo-, como se ha postulado en determinado sentido, para ámbitos de Europa: "La cruz como figura geométrica aparece con frecuencia en las construcciones arquitectónicas religiosas; sin embargo, también es motivo representado en lugares no específicamente religiosos, como en los caminos, los puentes y en los ambientes domésticos, donde surge de forma espontánea representada por devotos con medios, muchas veces, precarios, porque aunque en ocasiones su representación toma un rango de oficialidad, también en otras es una expresión de carácter íntimo y personal pero que, en cualquier caso, se hace público. Por último, aparece en las plantas de los edificios y en los trazados urbanos, como forma que se imagina o se visiona solo desde los documentos gráficos más elaborados: los planos” (Sánchez 2010: 18).

${ }^{6}$ Como sucede prácticamente en todos los pasos o puertos que tratamos, sus aledaños, "desechos" en la denominación topográfica, admiten tránsito hacia y desde la vertiente occidental andina. Además de la hoyada referida, hay otras posibilidades de paso por alturas cercanas, a las que accedemos por rumbos próximos, aunque esto implica aumentar los kilómetros de recorrido. Igualmente, puede accederse por las alturas a los otros pasos como el de Peña Negra y Comecaballos, tal como nosotros lo hicimos.

${ }^{7}$ En otra oportunidad dedicaremos tiempo y espacio a tratar varias de las enunciaciones del autor en ese y otros escritos -v.g., Bárcena 1995- sobre localizaciones de sitios y pasos incas que no concuerdan con registros previos y con los nuestros provenientes de constataciones de campo.

${ }^{8}$ Hemos subido el paso en varias oportunidades comprobando que puede acumular nieve en fechas tempranas con respecto a otros pasos, tal como sucede a principios de marzo. Al mismo tiempo, hemos registrando la posibilidad de utilizar varios pasajes a la vertiente occidental andina en la zona de La Ollita, algunos sobrepasan incluso los $4800 \mathrm{msnm}$.

${ }^{9}$ Sus prospecciones de altura le permitieron llegar en la mayoría de los pasos de que trata hasta el límite de nuestras naciones, Argentina y Chile. En el caso de La Ollita pudo divisar el lado argentino, apreciando "[...] vegas bien desarrolladas [...]” (Niemeyer 1986: 199). Esta afirmación coincide plenamente con nuestra experiencia de terreno, por la cual, además de lo que puede visualizarse vía imágenes satelitales, comprobamos extensas vegas en relación con los ríos y arroyos que venimos mencionando, en especial en el trayecto Peñas Negras/La Ollita. Esta situación permitiría 
asegurar mejores condiciones logísticas para el ganado, tanto en el primer paso colonial como en los posteriores, particularmente en la época de los referidos arreos, sin olvidar el sustrato específico para la supervivencia de los miles de camélidos del sector.

${ }^{10}$ Como expresamos, hay coincidencia en su papel de leal a la empresa. La crónica de su compañero de viaje, el clérigo Bartolomé de Segovia o Cristóbal de Molina, dice: "Y es de saber que aquel Paulo Inga, hermano del Inga, era un indio muy discreto y sabio y de mucho tono; fue con Almagro a las provincias y descubrimiento de Chile y pasó muchos trabajos en el viaje y sufriólos con buen ánimo; y, vuelto al Cuzco, le dieron las casas de Huáscar en que viviese, que eran las más principales casas del Cuzco" (Molina 1968 [1552]: 80-81).

${ }^{11}$ Posiblemente se trate del "cuerno de cabra", una especie de Adesmia ("acerillo") como la Adesmia subterránea o similares.

${ }^{12}$ Sobre la concepción hispana del espacio en los escritos de cronistas y con respecto a estas situaciones particulares de los dichos, tradición oral y referencias escritas de los primeros pasos de los Andes por los españoles, ver Vega (2011: 12), quien rememora alertar sobre el uso no crítico de estos escritos como reservorios de datos.

${ }^{13}$ No obstante, debe considerarse en las fuentes que algunas referencias del arribo de Almagro o de quienes le siguieron por el o los pasos, en realidad apuntan al cruce y al primer lugar de refacción de las huestes en Chile, que debió ser, como en algún caso se dice expresamente, valle arriba de Copayapo, más precisamente y como se propone modernamente, en la actual Iglesia Colorada, Choliguín de entonces.

${ }^{14}$ Una estimación grosera que una en línea recta las ubicaciones sobre imagen satelital Google, muestra que Copiapó dista unos $195 \mathrm{~km}$ del Paso de San Francisco en la actual Catamarca y unos $130 \mathrm{~km}$ de los Pasos de Pircas Negras y de Comecaballos en La Rioja.

${ }^{15} \mathrm{La}$ "amplitud" a la que nos referimos surge de la consideración de escala relativa con respecto a la infraestructura existente en los pasos propiamente dichos -máxima altura-, como es la prácticamente inexistente de Comecaballos, la reducida de Peña Negra o la apreciable al pie del paso de La Ollita. Si es por llamar la atención, por ejemplo, desde lo que podría ser más un aspecto ceremonial, votivo que, de infraestructura netamente utilitaria, destaca entre los pasos primero La Ollita con su posible ushnu -y más abajo su conspicuo tambo- y Pircas Negras, con lo que parece ser un trazo de camino indicado por piedras y estructuras aledañas. Pircas Negras es el único sector de paso donde puede compararse la relativa "llanada" de aproximación de unos 10 km de extensión, desde el paso a la caída a la quebrada del Río Salado, con la mención por parte de la crónica hispana de la "llanada" de la dificultad logística, indicada como transpuesta en sentido inverso.

${ }^{16} \mathrm{Si}$ nuestra interpretación es correcta y se trata solo del pasaje último de los Andes hacia Copiapó, Antonio de Herrera, tal como el mismo señala, sigue en su escrito tes- timonios, documentos y crónicas que le preceden sobre el tema. Afirma que el paso fue por "puertos" o por "dos puertos": "Pues todavía se hallaría en Copayapo Rodrigo Orgóñez respeto [sic] del tiempo que por dos puertos había que pasó", "ordenándoles que una vez entrados en los puertos" (Herrera 1901 [1601-1615]: 485). Vitry (2007: 13) adhiere a la postura de Cervellino (1994) en relación a que la logística de una movilización de la magnitud de la de Almagro implicaría el uso de dos pasos: Comecaballos y el de Pircas Negras distantes unos $13 \mathrm{~km}$. En su figura 4, Vitry (2007: 12) ubica el paso de Pircas Negras al sur de Comecaballos, cuando en realidad está al norte. Posiblemente se produjo la confusión con el paso de Peña Negra, que tiene una posición cercana y más austral que el de Comecaballos. Por nuestra parte, sostenemos que, cualquiera fuera el paso utilizado, la envergadura de la expedición supuso desplegar integrantes y bagaje de la expedición por los "desechos" de esos pasos o por pasos colindantes, más que por dos puertos que distan varios kilómetros entre sí. Recientemente hemos unido, con cierta facilidad, los pasos de La Ollita y de Peña Negra avanzando longitudinalmente de uno a otro por alturas intermedias y quedando al pie de los mismos en el trayecto final de las quebradas que permiten el ascenso por el último tramo transversal a Chile.

${ }^{17}$ Llama la atención que no se haya reparado suficientemente en un dato de Juan de Matienzo que refiere el itinerario por el Camino del Inca y los tambos asociados en el NOA. Según él, esta es la ruta que con toda probabilidad siguió Almagro en esta parte de su itinerario, tal como lo hizo más tarde Diego de Rojas -Levillier 1943-, virando éste hacia el río de la Plata y el otro hacia la cordillera de los Andes. Justamente ese dato de Matienzo, a partir de "los Talombones [sic], pueblo de indios" y de "los Tambos de la Ciénaga", "se aparta el camino del inga para la cibdad de Londres, y de allí para Chili, por la cordillera de Almagro, que dicen, sobre la mano derecha; y sobre la izquierda se toma el camino para Cañete y Santiago del Estero" (Matienzo 1987 [1556]: $207-$ 208). Con ello queda claro que, tan temprano como en 1566 (1536 paso de Almagro, 1543 pasaje de Rojas), ya se llamaba cordillera de Almagro a la parte de la cordillera de los Andes al oeste de Londres -fundada esta en 1558- y que por aquí el Camino del Inca tenía dirección occidental, como señalan los autores modernos (v.g., Raffino 2004; Vitry 2007). Pensamos que el itinerario a Copiapó, una vez llegados a Londres (El Shincal), sigue el rumbo al occidente del Camino Inca y no prueba la posibilidad de avanzar al noroeste por otro Camino Inca para alcanzar el paso de San Francisco. Es claro para nosotros que el rumbo que tomarían es directo hacia occidente y a los pasos entre La Ollita y Pircas Negras/ peñasco de Diego.

${ }^{18}$ Mariño de Lobera (2003 [1575-1576]: Cap. I, v: 2, 9) pudo haber agregado el dato con base en su conocimiento de Chile por haber ingresado en 1551 e integrado las huestes de Pedro de Valdivia en sus luchas del sur, prosiguiendo su 
colaboración con gobernadores sucesivos, para trasladarse a Perú después de 1575.

${ }^{19}$ Fernández de Oviedo relata que, "é habían escripto al adelantado que se adelantaban seguros con un indio orejón del Cuzco, á cuya subjeción estaba la dicha provincia de Pocayapo" (1901 [1557]: Cap. Iv: 227).

${ }^{20}$ Cieza de León (1909 [1553]: III Parte, cap. xcv) expresa que: "Partió Almagro descubriendo, llegó al valle de Coquimbo, donde había grandes aposentos de los incas", con lo que se refirma para esa época la envergadura de la instalación inca del Norte Chico y la relevancia política que pudo tener la sujeción del sector. Esta información es consistente con lo manifestado por los otros cronistas y con las comprobaciones arqueológicas en cuanto a su evidencia material. Del mismo modo, por los años en que escribe Cieza, en 1558 Bibar finaliza su obra de relación sobre los sucesos del Reino de Chile a partir de la conquista emprendida por Pedro de Valdivia, quien llega por el despoblado de Atacama a Copayapo en 1540. Si bien Bibar no es de la partida, pues llega más tarde a Chile, refleja muchos de los acontecimientos de esa época y refiere detalles significativos respecto del tema que nos ocupa, por ejemplo su alusión a que "entendiola porque habían tratado con indios del Cuzco porque tenían las diez y ocho leguas del valle de Copiapó un pueblo, como habemos dicho, de indios del Cuzco y, como con ellos trataban, entendía la lengua este capitán y otros muchos" (1966 [1558]: Cap. XIII: 21). Por otro lado, se menciona "los tambillos del Inga" "que cierran por el sur el perímetro del poblado" (Niemeyer et al. 1997: 253; refiriéndose a Copayapo). Estos últimos autores traen a colación las observaciones de Advis (1994) y de Cervellino (1994) según las cuales Almagro habría accedido primero en la bajada a Chile a Iglesia Colorada -punto que en rigor sería Choliguín y que las fuentes tempranas no registraron como tal- buscando pertrechos para auxiliar su campo, y no a Copayapo propiamente dicho (Niemeyer et al. 1997: 252). La información es respaldada, además, por la lectura atenta de las crónicas que enlazan el paso y primer contacto de la hueste almagrista con un área y población que se colige está valle arriba y antecede a la de Copayapo propiamente dicha, como ya hemos expresado anteriormente.

${ }^{21}$ Considerando lo que podríamos llamar el "tambo" propiamente dicho del noreste de la Laguna con RPC, estructura alargada pircada de base del tipo kallanka y similar dividida por bases de muros transversales, entre otras, estimando asimismo la relativa envergadura por las estructuras de carácter ceremonial con las del cerro Don Mario, entre otras (relevamientos y observaciones de Bárcena (1998, 2007, 2015), Beorchia Nigris (1987, 2001), Ceruti (2003), entre otros).

22 "Leña para hacer lumbre no había otra que estiércol de ovejas y unas raíces que sacaban debajo de tierra" (Cieza de León (1909 [1553]: Cap. XCv).

${ }^{23}$ Hoy el cercano Parque Nacional San Guillermo en el noroeste de San Juan y la Reserva Provincial Laguna Brava
-Reserva Provincial de Vicuñas y Protección del Ecosistema de Laguna Brava- en la parte de La Rioja a que nos referimos, son un reservorio importante de Vicugna vicugna, estimándose su número en varios miles, como ya hemos adelantado.

${ }^{24} \mathrm{~A}$ las construcciones pircadas y otros hallazgos de altura, señaladas por colegas en lugares prominentes de los cerros del área (Veladero, Don Mario, Don Nicolás, Pilar, Morado, entre otros; Beorchia Nigris 1985, 2001; Ceruti 2003; entre otros), sumamos algunas reconocidas por nosotros en torno a lagunas, como la construcción de base rectangular pircada por muro de doble hilera de piedras, sita en la ribera sur de una gran laguna ubicada al sureste del Paso de La Ollita (fig. 12).

${ }^{25}$ Seguramente pueda seguirse en documentación de archivo las épocas del uso de la denominación Comecaballos para el Paso y llegarse a certezas sobre el apelativo. Sin un esfuerzo de indagación especial, sabemos que el derrotero de una parte menor de las fuerzas del General San Martín en su avance sobre Copiapó, se hizo por el Paso de Comecaballos, al que llaman así en el plan de campaña de principios del siglo xix (v.g.: Bertling 1917: 40 -Come-Caballos-) y que, al menos en cuanto a la denominación, ya estaba en uso a fines del XIx, aunque usada generalmente como Come Caballos (v.g.: Espinoza 1897: 111, 112).

\section{REFERENCIAS}

ADvis, P., 1994. Noticias de cronistas e historiadores sobre la travesía de los Andes realizada por la hueste de Almagro durante la Jornada de Chile. Boletín del Museo Regional de Atacama 4: 103-127. Copiapó.

Bárcena, J., 1998. Arqueología de Mendoza. Las dataciones absolutas y sus alcances. Serie Manuales 19. Mendoza: Universidad Nacional de Cuyo.

BÁrCEnA, J., 2007. Avances 2005-2007 sobre arqueología y etnohistoria de la dominación inka del centro oeste argentino: arquitectura y vialidad en La Rioja, San Juan y Mendoza. Pacarina II: 493-499. Jujuy.

BÁRCENA, J., 2015. Investigaciones en los pasos cordilleranos de La Rioja y San Juan: sitios inka de Comecaballos, La Ollita y Santa Rosa. Arqueología, patrimonio cultural y minería. Xama Serie Monografías 5: 199-232. INCIHUSA-CONICET.

BeORChIA Nigris, A., 1987. El enigma de los santuarios indígenas de alta montaña. San Juan: Universidad Nacional de San Juan.

Beorchia Nigris, A., 2001. La saga del Veladero. En Arqueología de alta montaña, A. Beorchia Nigris, Ed., pp. 213-230. San Juan: CIADAM.

Bertling, H., 1917. Estudio sobre el paso de la Cordillera de los Andes efectuado por el Jeneral San Martín en los meses de enero y febrero de 1817 (campaña de Chacabuco). Santiago: Talleres del Estado Mayor General.

Ceruti, C., 2003. Santuarios de altura en la Región de la Laguna Brava (Provincia de La Rioja, Noroeste Argen- 
tino). Informe de prospección preliminar. Chungara 35 (2): 233-252. Arica.

Cervellino, M. 1994. Relatos de una expedición: Almagro en los Andes, por la ruta de la muerte. Boletín del Museo Regional de Atacama 4: 129-140. Copiapó.

Cieza de León, P., 1877 [1553]. Tercer libro de las guerras civiles del Perú, el cual se llama la guerra de Quito. Hecho por Pedro Cieza de León, cronista de las cosas de las Indias. Madrid: Imprenta de M. G. Hernández.

Espinoza, E., 1897. Jeografía descriptiva de la República de Chile. Santiago: Imprenta Encuadernación Barcelona.

Fernández de Oviedo y VAldés, G., 1901 [1557]. Historia general y natural de las Indias. Islas y tierra firme del mar océano. Colección de historiadores de Chile y de documentos relativos a la historia nacional, tomo xxvII, pp. 1-253. Santiago: Imprenta Elzeviriana.

Gambier, M. \& C. Michieli, 1992. Formas de dominación incaica en la provincia de San Juan, Argentina. Publicaciones 1: 11-19. San Juan: Universidad Nacional de San Juan.

Herrera, A. DE., 1901 [1601-1615]. Descripción de las islas y tierra firme del mar océano que llaman Indias Occidentales. Colección de Historiadores de Chile y de Documentos relativos a la Historia Nacional, tomo XxvII, pp. 329-556. Santiago de Chile: Imprenta Elzeviriana.

LeVillier, R., 1943. Descubrimiento y población del norte argentino por españoles del Perú. Desde la entrada al Tucumán hasta la fundación de Santiago del Estero: 1543-1553. Buenos Aires: Espasa-Calpe.

López de Gomara, F., 1901 [1552]. Hispania victrix. Primera y segunda parte de la Historia general de las Indias con todo el descubrimiento, y cosas notables que han acaescido dende que se ganaron hasta el año de 1551, con la conquista de Mexico, $y$ de la nueua España. Colección de historiadores de Chile y de documentos relativos a la historia nacional, Tomo XXVII, pp. 267-293. Santiago de Chile: Imprenta Elzeviriana.

Mariño de Lobera, P., 2003 [1575-1576]. Crónica del Reino de Chile. Libro Primero. <www.biblioteca.org.ar/libros/89677. pdf $>$ [Consultado 13-04-2017].

Matienzo, J. DE., 1987 [1556]. Carta a S.M. del licenciado Matienzo oidor de charcas [...]. En Crónicas del Tucumán, siglo XVI, E. Berberián, Ed., pp. 203-213. Córdoba: Comechingonia.

MolinA, C. DE., 1968 [1552]. Relación de muchas cosas acaecidas en el Perú. Biblioteca de Autores Españoles, tomo CCIx. Madrid: Atlas.

Niemeyer, H., 1986. La ocupación incaica de la cuenca alta del Río Copiapó (III ${ }^{a}$ Región de Atacama, Chile). Comechingonia, pp. 165-294. Córdoba.

Niemeyer, H.; M. Cervellino \& G. Castillo, 1997. Culturas prehistóricas de Copiapó. Copiapó: Museo Regional de Atacama.

RAfFino, R., 1995. Inka road research and Almagro's route between Argentina and Chile. Tawantinsuyu 1: 36-45. Canberra.
Raffino, R., 2004. El descubrimiento. Diego de Almagro y la invasión española. En El Shincal de Quimivil, R. Raffino, Ed., pp. 45-67. Catamarca: Sarquis.

Raffino, R.; R. Iturriza, A. Capparelli, J. Gobbo, V. MonTES, C. Diez \& A. IÁcona, 2001. El Capacñam Inka en el riñón valliserrano del Noroeste Argentino. En Historia argentina prehispánica, E. Berberián \& A. Nielsen, Dirs., Tomo II, pp. 493-521. Córdoba: Brujas.

Revuelta, C., 2007-2008. Arte rupestre de arrieros históricos en La Rioja. Nuevos sitios y descripción preliminar para su estudio en la Provincia. Novedades (58): 9-11. Buenos Aires.

SÁncheZ, J., 2010. La cruz como ícono protector en los espacios de tránsito. Estudios del patrimonio cultural 5: 18-30. $<$ http://sercam.es/estudios-del-patrimonio-cultural/epc05/> [Consultado 12-04-2017].

Stuiver, M. \& H. Polach, 1977. Discussion reportinf of 14C data. Radiocarbon 19 (3): 355-363.

Vega, A., 2011. Experiencias de cordillera, ecos de frío: relatos cruzados entre Chile y Quito en el siglo XVI. Revista Chilena de Literatura 80: 223-242.

Vitry, C., 2007. La ruta de Diego de Almagro en el territorio argentino: un aporte desde la perspectiva de los caminos prehispánicos. Revista Escuela de Historia 6 (1). Salta: Universidad Nacional de Salta. <www.unsa.edu.ar/histocat/revista/revista0615.htm> [Consultado 13-04-2017].

Zárate, A. DE., 1901 [1555]. Historia del descubrimiento y conquista de la Provincia del Perú y de las guerras y cosas señaladas en ellas, acaecidas hasta el vencimiento de Gonzalo Pizarro y de sus secuaces, que en ella se rebelaron contra Su Majestad. Colección de historiadores de Chile y de documentos relativos a la historia nacional, Tomo xxvII, pp. 255-265. Santiago de Chile: Imprenta Elzeviriana. 